Illinois State University

ISU ReD: Research and eData

Theses and Dissertations

4-7-2020

\title{
"Don't Stop Believin"' in a pair of socks: How The Sopranos shapes our understanding of mental illness
}

Adam Richard Brockman

Illinois State University, brockmanadamr@gmail.com

Follow this and additional works at: https://ir.library.illinoisstate.edu/etd

Part of the Communication Commons

\section{Recommended Citation}

Brockman, Adam Richard, "'Don't Stop Believin'" in a pair of socks: How The Sopranos shapes our understanding of mental illness" (2020). Theses and Dissertations. 1247.

https://ir.library.illinoisstate.edu/etd/1247

This Thesis is brought to you for free and open access by ISU ReD: Research and eData. It has been accepted for inclusion in Theses and Dissertations by an authorized administrator of ISU ReD: Research and eData. For more information, please contact ISUReD@ilstu.edu. 


\section{“DON'T STOP BELIEVIN"” IN A PAIR OF SOCKS: HOW THE SOPRANOS SHAPES OUR UNDERSTANDING OF MENTAL ILLNESS}

\section{ADAM RICHARD BROCKMAN}

\section{Pages}

This study rhetorically analyzed the final season of The Sopranos for its argument about the nature of psychological depression in several contexts and forms. Consisting of nine episodes, the final season of the series features pivotal moments in which characters confront the sources of their depression and respond to them in a variety of ways. The study used both an intertextual analysis and Burkean frames to provide insight into how the final season argues one might overcome various forms of depression. It specifically considered depression related to one's family experiences, their existential concerns regarding death and spirituality, and their indulgence in contemporary media platforms. The study's general implications and applications to future research are also discussed.

KEYWORDS: The Sopranos, depression, mental illness, television, rhetorical analysis, rhetorical criticism 
"DON'T STOP BELIEVIN"” IN A PAIR OF SOCKS: HOW THE SOPRANOS SHAPES OUR UNDERSTANDING OF MENTAL ILLNESS

ADAM RICHARD BROCKMAN

A Thesis Submitted in Partial Fulfillment of the Requirements for the Degree of

\section{MASTER OF SCIENCE}

School of Communication

ILLINOIS STATE UNIVERSITY 
Copyright 2020 Adam Richard Brockman 
"DON'T STOP BELIEVIN"” IN A PAIR OF SOCKS: HOW THE SOPRANOS SHAPES OUR UNDERSTANDING OF MENTAL ILLNESS

ADAM RICHARD BROCKMAN

COMMITTEE MEMBERS:

Phillip J. Chidester, Chair

Brent K. Simonds

Joseph P. Zompetti 


\section{ACKNOWLEDGMENTS}

First, thank you Dr. Chidester for being the chair of my thesis committee. Our meetings were often the highlight of my week, and not just because of our occasional off-topic discussions. I knew my chair needed to be an expert on all things Burke, rhetoric, and media studies, but also someone who would allow me to be creative and adapt to my chaotic personality. Somehow our conversations about the crafting mechanics in Red Dead Redemption II always led back to my rhetorical analysis of The Sopranos, and I can guarantee this project would not have possessed the necessary insight without those meetings.

Thank you to my committee members, Dr. Simonds and Dr. Zompetti. Dr. Simonds, your media ecology seminar challenged me to consider the intricate ways we consume television programs (among other visual media), and our general conversations about the latest Oscarnominated films and award-winning documentaries reminded me how much I enjoy this topic. Dr. Zompetti, your course in rhetorical methods gave me the theoretical framework for this project and taught me the attention to detail required for an analysis of this level. Also, I will never forget coming to your office the first time to discuss my thesis and you told me I needed to narrow my topic a great deal for it to work. Then you told me you knew I would figure it out. That balance of rigor and guidance gave me the confidence to complete my thesis.

I also have to thank those who made my time in graduate school the engaging, enlightening experience it was, without which this project would not have existed. Dr. McHale, teaching the lab section of your convergent media writing course constantly inspired me to think about the form of mass media messages and what constitutes a good story. Even after teaching for three straight hours every Friday, I left each lab session feeling more energized and inspired than ever to continue my analysis of The Sopranos. Bruce, Hasnaa, and Misha - thank you for 
being such great office mates and listening to all my random stories. I hope you know how much those little things mean to me.

And finally, thank you to Ben Lynn. Ben, simply put, you are the reason I pursued my master's degree. When you reached out to me about grad school, I just had spent six months searching for any job I could get and panicking that I was 23 years old and had no idea what to do with my life. You helped me with the application and emailed me to see how things were going when I started the program. And now that I am finishing the program, every one of my major career developments in teaching, writing, and instructional design happened because of it. I cannot thank you enough.

A. R. B. 


\section{CONTENTS}

Page

ACKNOWLEDGMENTS

CHAPTER I: INTRODUCTION

CHAPTER II: LITERATURE REVIEW

Mental Illness as an American Concern

Connection Between Television and Mental Illness

Rhetorical Analysis of Mental Illness

Analysis of General Mental Health Texts

Rhetorical Analysis of Mental Illness in Literature

Rhetorical Analysis of Mental Illness in Film

Rhetorical Studies of Television Dramas

Cultural and Generic Norms of the Gangster Genre

Existing Research on The Sopranos

Conclusion

CHAPTER III: METHODS 
Characters and their Surrogate Children

Depression Resulting from an Existential Crisis $\quad 55$

Religious and Spiritual Imagery $\quad 57$

"Strangers" to the "Absurdity of Life" 58

The Tragedy of Material Goods $\quad 64$

The Relationship Between Media Platforms and Depression 69

Media Platforms as Tools for Coping with Depression 71

Depression’s “Second Coming” $\quad 74$

Media Platforms as a Scapegoat $\quad 76$

$\begin{array}{ll}\text { Taking Advice from Television } & 79\end{array}$

CHAPTER V: DISCUSSION 28

Directions for Future Research $\quad 85$

“Just a TV Show” $\quad 88$

$\begin{array}{ll}\text { REFERENCES } & 91\end{array}$ 


\section{CHAPTER I: INTRODUCTION}

One of my fondest memories is the first (and only) time I told myself I just witnessed the greatest hour of television of all time. The episode in question is the third-to-last episode of Breaking Bad (titled “Ozymandias”), a critically acclaimed drama series about a high school chemistry teacher who resorts to manufacturing methamphetamines after being diagnosed with terminal lung cancer. This groundbreaking episode culminates in a variety of character and plotdefining moments that had both viewers and critics proving I was not alone in my praise of the episode. I marveled at the episode's excellence and have never had the same immediate reaction to any episode of any series in the six years since it aired.

I started watching The Sopranos not long after Breaking Bad ended, probably to fill the void with one of the few acclaimed series I had not seen. The show follows Tony Soprano, a middle-aged leader of a New Jersey-based organized crime family. Tony seems to have acquired the American Dream at the beginning of the series - he has a wife and two children and lives in a luxurious house in an affluent suburban neighborhood. And yet, he suffers from depression and sees a therapist to treat his chronic panic attacks. The series arguably poses a more subtle and less melodramatic question than Breaking Bad's premise: instead of speculating if the main character will commit enough crimes to provide for his family, we wonder if Tony will complete the necessary analysis and self-reflection in therapy to cure (or at least treat) his mental illness.

The answer to that question is what prompted me to conduct this study. I wanted to determine if Tony uses the insight he gains from his several years in therapy to treat his depression or if his rejection of those therapeutic techniques will condemn him to a life of misery. More specifically, I wanted to discover what the text has to say about the process of overcoming depression in general - do those afflicted with depression need to accept a nihilistic 
worldview to find happiness? Do they need to stop idolizing their parents and embrace a new set of family values? This study's primary goal was to answer these questions (and raise more to inspire future research) through a rhetorical analysis of the show's final season, which is perhaps the most prominent depiction of Tony's depression.

More specifically, this rhetorical analysis focused on three forms of depression the final season depicts through its main characters: depression as a result of one's family upbringing, depression as a result of an existential crisis, and the relationship between depression and the use of contemporary media platforms. This project's purpose was to determine the final season's argument regarding how depressive symptoms might exist in these different contexts, as well as how those suffering from them might attempt to alleviate their effects. While concrete, definitive answers to these questions might not exist in the final season of The Sopranos, the endgame of this thesis was to reveal more original, profound insight on the season's portrayal of depression than what currently exists in the discourse surrounding the series.

The final season of The Sopranos also inspired this study for its relatively odd structure. Although some television programs elevate the plot's conflict to its peak in their final seasons, The Sopranos uses its denouement to ambiguously reveal insight regarding its protagonist's goals. I was never breathing intensely or digging my nails into the arm of my couch during the final season of The Sopranos like I would do while watching Breaking Bad. However, like Breaking Bad, The Sopranos reserves one of its final episodes as the show's unofficial ending. The fourth-to-last episode of The Sopranos, entitled "Kennedy and Heidi," depicts Tony murdering his nephew Christopher (a key character from the beginning of the series) and escaping to Las Vegas where he ingests peyote, has sex with one of Christopher's ex-girlfriends, wins copious amounts of money at the roulette wheel, and laughs hysterically as he watches the 
sun rise and screams "I get it!" (Chase, 2007). As I watched Tony utter this now iconic phrase, I said to myself, "Well, I don't get it." Whereas I was floored by the thematic consistency and grandiose plot development of "Ozymandias" the minute I watched the credits roll, I stared at the screen in confusion after watching "Kennedy and Heidi."

But for a few years after finishing The Sopranos, I found myself periodically reading about the series online. I would be eating lunch between classes searching for the latest think pieces and retrospective reviews. I would scan one of the many Reddit threads trying to make sense of Tony's infamous three words during his peyote trip. Was this Tony's most prolific breakthrough after years of therapy where he realizes the source of his depression? Was it nothing more than a hallucinogenic experience that made sense at the time but had no lasting impact on his psyche? Whatever it was, I knew I was missing something about that episode and its connection to all the ideas about depression the series poses in the pilot. I had no idea what the answers were, but the episode challenged, fascinated, and inspired me to learn more about the ambiguity of the show's final season. And although I never had the immediate infatuation with the series that I did with Breaking Bad, I spent countless more hours studying The Sopranos, making me wonder if The Sopranos is an artistic achievement more worthy of a scholarly approach than the other shows I consciously enjoyed but never thought about for more than 30 minutes after they ended.

Of course, with a program as complex as The Sopranos, there are myriad topics this study could have observed. Race, sexuality, and hegemony are only a few subjects the series explores in addition to its premise. And although those topics are all prime targets for research in several disciplines, it was Tony's journey through therapy that challenged me the most. It made me wonder if clinical depression could be rooted so deeply in one's chemical makeup that no 
amount of therapy or medication can treat it. It challenged me to consider how one's family upbringing could alleviate symptoms of depression while simultaneously being a harbinger of mental illness. It inspired me to reflect on my own experience with mental illness more critically than any form of art or entertainment had done before. Rather than watching an episode and thinking, "Wow, I relate to that," I would wonder if I seek out relationships with chaotic, unstable individuals because of my mother's narcissism. I would contemplate if I subconsciously bring up morbid stories at the dinner table because of my own envy at seeing other people enjoy themselves. The Sopranos was never a substitute for therapy, but its nuanced portrayal of the subject was a catalyst for me to learn more about the potential sources of depression and the process of overcoming it.

It is no surprise that The Sopranos demands such a level of analysis, given its cultural impact from its inception. It pioneered the Third Golden Age of Television and the proliferation of cable dramas in the $21^{\text {st }}$ century (Martin, 2014). It made HBO (and, by extension, basic cable platforms like AMC and FX) a hub for complex original programming instead of reruns of old films. But perhaps more importantly, it proved a television show could possess literary merit and still attract a wide audience (Weiner, 2011). It had enough faith in its viewers to avoid "spoonfeeding" them its thoughts on the human condition and trust they would still pay the premium cable fee and tune in every Sunday. This approach helped the series reach almost 12 million viewers in its finale ("Sopranos ratings," 2007) and win 21 Emmy Awards ("The Sopranos," 2020).

None of this success is more evident than in the reception of the show's finale. The final scene of the series depicts Tony and his family eating dinner at a diner in New Jersey. Tony looks around at the many strangers in the diner and plays Journey's "Don't Stop Believin"” on 
the jukebox. He eyes each of the diner's patrons with a paranoid expression, as if any of them could be an assassin plotting to exact revenge on behalf of one of the many enemies Tony has made. Then suddenly the screen cuts to black, removing the audio and video for about ten seconds before the credits roll (Chase, 2007). Many viewers thought their cable malfunctioned at the worst possible moment (Carter, 2007). Others were outraged and used HBO's online message boards to express their hatred of the ending ("Fans outraged," 2007). Some considered the ending a "middle finger" to a loyal fanbase that had watched the show religiously for seven years ("Sopranos creator," 2007), and many critics who previously praised the show viewed the ending as a "cop out" (Ryan, 2007; Zoromski, 2007), as if series creator David Chase could not decide on a definitive ending and avoided writing one altogether.

However, while several fans and critics viewed the ending as one of television's greatest disappointments, the finale's ambiguity kept viewers interested long after the last episode aired. Fan theories started suggesting that Tony died in the diner, identifying numerous clues throughout the series hinting toward this conclusion (Gorman, 2007). Chase has yet to respond directly to these theories and confirm or deny Tony's fate (Egner, 2019; Sepinwall, 2007), claiming that all the information the viewer needs exists in the ending itself. But regardless of the answer to the "Does Tony Die?" debate, the show is still celebrated and scrutinized over a decade after it ended. The Today Show conducted an interview with many of the series' cast members in 2019 in honor of the $20^{\text {th }}$ anniversary of the show's premiere (Blistein, 2019). The cast also appeared at HBO’s annual Split Screens Festival in 2019 (Armstrong, 2019), proving that despite the network's more recent success with original programming like Game of Thrones and Westworld, The Sopranos is still a culturally relevant text years after its conclusion. Likewise, The New York Times published a list of other innovative television dramas that likely 
would not have existed without The Sopranos pushing the boundaries of what was possible in the medium ("The 20 best TV dramas," 2019). Therefore, some might argue that a show that has been over for longer than it ever aired lacks the cultural relevance to be studied rhetorically, but its lasting impact on one of the most popular entertainment platforms indicates its worth as a thematically rich text. The program's existing popularity among both critics and fans could continue to challenge a variety of audiences' assumptions about mental illness and further the discourse about how individuals and societies perceive the nature of mental illness and the capacity to overcome it.

Despite the long-term conversation The Sopranos (specifically its ending) has created, this study tackled one aspect that seems to have diminished its impact. Because of the ambiguity surrounding the ending, much of the show's discussion revolves around a plot detail (does Tony die?) rather than the intellectual themes the show spent seven years covering. For a series about a depressed mafia leader who can only express affection through animals because his mother was incapable of loving him, The Sopranos appears to have been reduced to a surprisingly pat conclusion. It is as if some of the show's discourse is treated as a puzzle to be solved rather than a complex artifact to be studied. As a result, this study examined the final season of The Sopranos to connect it to the initial questions the show poses: what is the source of Tony's depression and can it be cured? Given their inability to be scientifically proven, the answers to these questions might be no clearer than Tony's literal fate at the end of the series. The same way we might never know if Tony is alive and well or lying dead in a plate of onion rings, we might remain forever ignorant of what exactly Chase and his writers hoped to inform us about the nature of depression. Perhaps, though, the inability to excavate simple, concrete meanings from 
The Sopranos indicates both the complexity of the series and this study's potential to enlighten and expand upon discussions revolving around mental illness.

That foundation is why this project's ramifications could extend beyond the realms of media studies and communication research. There might be rhetoric scholars with a voracious appetite for new insights into the depiction of mental illness in contemporary media. But there might also be someone who fell in love with their therapist and realized they can no longer confide in the person they pay to listen to them. They might loathe themselves for succumbing to something they fail to understand, something that results from their parents' refusal to acknowledge major depression as anything other than "the blues" or "teenage angst." There might be someone who frequently wakes up at 2 a.m. to realize (as if for the first time) that they could die at any moment and leave behind a minimal legacy. There might be someone who spends that same hour watching Facial Flex infomercials because it is the only distraction from the incessant and debilitating fear that everyone they love will abruptly abandon them. Though a rhetorical analysis of a television series could never compensate for therapy, it could help individuals struggling with depression understand the endless, complex sources of its symptoms. Treating Tony Soprano as a case study could convince them to explore new ways of understanding the origins of mental illness. This process might even be what inspires both communication researchers and mental health professionals to further evaluate the presentations (and potential consequences) of such depictions of mental illness through television. In any case, an analysis of a mafia leader's panic attacks might be the missing ingredient to understanding mental illness in a variety of fields when it seems all other avenues have been exhausted. 


\section{CHAPTER II: LITERATURE REVIEW}

Although this study aims to present a unique angle on a television series, its subject matter stems from a variety of other fields. Mental illness alone could signify a plethora of meanings for different audiences, and the analysis of a television series might bring to mind several conflicting methods and procedures. Thus, the purpose of this literature review is to explain the aspects of mental illness and their connection to television narratives that relate to this study. Because this study is specifically concerned with depression, it distinguishes between this form of mental illness and other ailments and describes its prevalence in American culture. The ubiquity of conversations about mental illness is evidenced by the numerous studies of representations of various illnesses on television. The literature review expands on this research by examining existing rhetorical analyses of mental health in fictional and dramatic narratives. However, the vast majority of that research revolves around film, poetry, and literature. These studies lay the groundwork for a study like the present one to apply similar methods to television drama. Ultimately, despite the abundance of research on mental health as it relates to television and other forms of mass media, little of this research rhetorically analyzes television dramas for their argument surrounding depression and the process of overcoming it, a void this study is designed to fill.

This chapter consequently begins with a discussion of mental illness as an American concern, detailing the prevalence of psychological disorders and their relationship to prominent events in American culture. It then examines the general relationship between television and mental illness in terms of representations of mentally ill characters on screen and their effect on audience attitudes about the subject. The literature review then discusses how scholars have rhetorically analyzed texts about mental illness, such as political speeches, novels, films, and the 
few examples in dramatic television. The chapter ends by describing existing research on cultural and generic norms within the gangster genre of popular American films as well as research specifically about The Sopranos.

\section{Mental IIlness as an American Concern}

Mental illness might refer to a number of concerns for different publics, but it generally indicates a psychological disorder that impairs one's thoughts, mood, and overall behavior (Mayo Clinic, 2020). While not unique to Western cultures, mental illness of all forms is a prominent concern for many Americans. Over 25 percent of American adults suffer from a mental disorder each year, with many of them possessing a combination of depressive, anxiety, and substance abuse disorders (John Hopkins Medicine, 2020). Mental illnesses can also result from a number of factors, such as brain chemistry, unstable environmental conditions in one's youth (or even before birth), and the inheritance of genetic traits (Mayo Clinic, 2020).

Depression itself exists in a variety of forms. The most severe is typically major depression, categorized by constant feelings of emptiness, loneliness, and guilt (Harvard Health, 2018). Individuals might also suffer from persistent depressive disorder, a less severe but consistently present form of major depression symptoms (Harvard Health, 2018). Bipolar disorder refers to one's dramatic (and sometimes violent) shifts between manic and depressive phases, while seasonal affective disorder involves a greater severity of depressive symptoms in conjunction with specific seasons (Harvard Health, 2018).

The cultural impact of mental illness in America is not limited to its ubiquity. The subject is also linked to other prominent topics. As the $10^{\text {th }}$ most common cause of death in the U.S., suicide is often associated with mental disorders like depression and illnesses related to alcohol abuse (American Psychiatric Association, 2018). Since 2006, the suicide rate has increased each 
year, with almost 45,000 people committing suicide in the U.S. in 2016 (American Psychiatric Association, 2018). Considering mental illness can be a contributing factor to the prevalence of suicide, studies examining mental illness could literally have life-changing consequences. However, mental illness has several connections to other American concerns beyond suicide. Various types of relationships are challenged when an individual suffers from a mental illness. Parents often feel ashamed, embarrassed, and guilty when their child is mentally ill, with some parents even enduring a grieving process when they are unsure how to help their child (Glynn, Kangas, \& Picket, 2020). Likewise, children of mentally ill parents are more likely to develop mental illnesses themselves than those without mentally ill parents (American Academy of Child \& Adolescent Psychiatry, 2015). A chaotic, unpredictable family environment can exacerbate symptoms of mental illness in children (American Academy of Child \& Adolescent Psychiatry, 2015), indicating that mental illness affects far more than the individual suffering from it. In fact, romantic relationships tend to suffer as well. Doohan, Carrère, and Riggs (2010) found a negative association between marital satisfaction and "flooding" (a process where one's negative attitudes and disposition contagiously affect their partner). Those without a mental illness are therefore likely to be emotionally and negatively affected by their partners' illnesses.

The interpersonal effects of mental illness extend beyond familial and romantic relationships. A national survey from 2006 revealed that the majority of Americans feared that individuals with schizophrenia would likely act violently toward others, with $32 \%$ believing the same prospect for individuals with major depression (Harvard Health, 2011). Current research indicates, however, that violence is not a common characteristic of those with a mental illness (Harvard Health, 2011) and that the public tends to exaggerate the connections between violence and mental illness (Stuart, 2003). The debate about these connections has reached some of the 
most prominent public policy issues in the country. In 2019, US President Donald Trump blamed mental illness as the primary cause of mass shootings, whereas several professors and psychiatric professionals argued that this perspective functions to scapegoat those with a mental illness and avoid necessary changes to gun control laws (Thomas, 2019). Therefore, with its myriad connections to other significant topics like suicide and mass shootings, mental illness has become an arguably crucial concern in American culture.

The depiction of mental illness on a television program might not seem as pressing as understanding its connection to large-scale public policy concerns, but given that those concerns often stem from mental illnesses, determining what that program has to say about the topic (or what it is trying to "do" about it) might bring individuals from a variety of fields closer to understanding the enigma of mental illness. An analysis of a program about mental illness could help a grief-stricken mother transform her rage into empathy for her daughter suffering from major depression. Policymakers might see mental illness for the complex problem it is and discover more effective and nuanced ways to assist those struggling with it. Therefore, to help spark this change and create a more challenging and thoughtful discourse surrounding mental illness, this study consequently applies its rhetorical model to several different sources and forms of depression presented in The Sopranos.

\section{Connection Between Television and Mental Illness}

Although studies surrounding The Sopranos and its depiction of mental illness are largely absent, scholars from several disciplines have examined the general connection between television and mental illness. Much of this research relates to representations of individuals with a mental illness on television. Many researchers, for instance, have found that some television shows stigmatize mental illness. Sieff (2003) found that media frames, including those in 
television, can contribute to negative public attitudes about mental illness. Pirkis, Blood, Francis, and McCallum (2006) found a predominantly stigmatizing portrayal of characters with mental illness on fictional film and television programs and speculated about the ramifications these portrayals could have on viewers seeking help for their mental health. In fact, television programs generally overemphasize the role of medication in treating mental illness instead of other support services (Henderson, 2018). Television portrayals also tend to correlate mental illness with violent crime, with mentally ill characters being almost 10 times as likely to commit violent crimes compared to other television characters (Diefenbach, 1997). Other studies have found similar results about the prevalence of television programs depicting mental illness as violent (Signorielli, 1989; Wilson, Nairn, Coverdale, \& Panapa, 1999a; Wondemaghen, 2019; Parrott \& Parrott, 2015). Wilson et al. (1999a) found that television programs often depict mentally ill characters as lacking in comprehension skills and seeming unproductive, unpredictable, and asocial. Although such studies demonstrate the value of studying mental illness on television, this study expands on this cultural conversation by dissecting the overall argument about depression and the process of overcoming it as expressed through The Sopranos.

Other researchers have criticized the establishment of stereotypes about mental illness in popular television programs. Wilson, Nairn, Coverdale, and Panapa (2000) also found that children's programs often portray mentally ill characters as "crazy," "mad," or "losing their minds," a concern for many researchers given that negative attitudes toward those suffering from mental illness typically develop in early childhood (Wahl, Hanrahan, Karl, Lasher, \& Swaye, 2007). Of course, The Sopranos contains enough violence and nudity for most viewers to agree it is not intended for children. However, because of the critical interest in negative stereotypes in every form of television programming from crime dramas to children's programs, the discourse 
surrounding mental illness on television is still a significant topic worth studying. In fact, given the widespread concern about television programs like 13 Reasons Why and their potential to instill suicidal thoughts and ideation in viewers (Ferguson, 2018; Bridge et al., 2019; Beal, 2018; Walker \& Burns, 2019; Notredame, Grandgenèvre, Vaiva, \& Séguin, 2018; Cooper, Bard, Wallace, Gillaspy, \& Deleon 2019), contemporary scholars will likely be interested in such critical depictions for years to come.

Research on presentations of mental illness on television has also focused on empowering and destigmatizing portrayals of specific disorders. Salter and Byrne (2000) even claimed that television (among other forms of media) can challenge prejudices regarding mental illness and foster a healthy discussion on the topic. For instance, Amanullah (2010) argued that the writers of the television program House allow the titular character's narcissism to serve as a source of his genius in solving complex medical problems. A study from Spieker (2017) revealed that some television characters use their mental illness as a superpower. Kaplan (2007) found that television programs like Boston Legal and Grey's Anatomy have relied heavily on consultants to avoid stereotypes in narratives about mental illness. Scholars have also examined the potential effects of this destigmatization. Hoffner and Cohen (2015) found that viewers' strong bonds with the titular character of the television series Monk resulted in fewer stereotypes about mental illness. A study by Wahl and Lefkowits (1989) speculated on the effectiveness of corrective actions television writers and other content creators can take to reduce the stigma surrounding mental illness, further illuminating the long-term scholarly conversation about mental illness on television.

Although this study's focus revolves around television, scholars have examined more contemporary types of media texts for their portrayals of characters with mental illness. One of 
those channels is video games. Dunlap (2018) argued that scholars have largely ignored video games' potential to affect cultural attitudes toward mental illness. Because video games often rely on clinical settings and terminology as plot devices, Dunlap (2018) found, researchers should consider how this popular and continuously expanding platform could shape gamers' perceptions of mental illness. Similarly, Shapiro and Rotter (2016) analyzed the 50 best-selling video games from 2011 to 2013 , finding that 42 characters across those games seemed to possess a mental illness. The researchers created categories for those depictions ranging from "homicidal maniac" to "narcissistic parasite" to "paranoid conspiracy theorist." Ferrari et al. (2019) sampled 100 games in 2016 and 2017 and found that 97 of them were misleading or problematic in their portrayal of mentally ill characters as violent, insane, or hopeless. Cheang and Doshi (2020) evaluated the game Hellblade: Senua's Sacrifice, an action-adventure game about a woman suffering from psychosis. The researchers found that the game accurately portrays psychosis with its surreal atmosphere and its refusal to "fix" the protagonist's mental illness (Cheang \& Doshi, 2020). Cheang and Doshi (2020) also found that although the gameplay involves combat, the protagonist is not portrayed as abnormally or irrationally violent. Thus, the discourse surrounding how contemporary media texts use both their form and content to present ideas related to mental illness has evolved in recent years. This study, then, aims to expand on this discourse not only by applying it to The Sopranos, but by analyzing the series rhetorically to determine its overall argument concerning the treatment of mental illness.

\section{Rhetorical Analysis of Mental Illness}

With their ability to reach a wide audience, the aforementioned television programs are in a position to change the way viewers think about mental illness. These programs could be the driving factor that changes inflated perceptions about the association between mental illness and 
violence. However, because the studies of these media texts focus on representations, they do not necessarily consider the thoughts and behaviors these texts hope to instill in their viewers. Therefore, approaching similar texts from a rhetorical perspective might provide a better understanding of a television program's discursive agency. While not necessarily related to television, other studies have considered the rhetorical argument posed about depression by other types of texts.

\section{Analysis of General Mental Health Texts}

Although the rhetorical analysis of arguments regarding mental illness in television is largely absent, several scholars have rhetorically examined other texts for their arguments related to mental health. Dumit (2002) analyzed the use of brain images in books and magazines, claiming these images' persuasive power attempts to establish a "pharmaceutical self" within the viewer and make them reconsider the cause of their mental illness. Lueck (2018) contrasted the persuasive strategies of gain and loss framing used in health communication to combat depression. The researcher found that a gain-frame advantage strategy presented a more effective argument to combat both mild and severe depression, arguing that mental health messages should be uniquely presented to individuals at each stage of depression (Lueck, 2018). These studies exist in a much different context than dramatic television, but they do illustrate the application of rhetorical methods to the conversation surrounding mental health.

Other scholars have examined the rhetorical characteristics of narratives about mental illness. White (2008a) researched how women with a mental illness write autobiographies to narrate their experiences and reclaim their identity. White (2008a) argues in this study that these autobiographies act as manifestos to establish a "discursive resistance" for women suffering from mental illness. Likewise, Johnson (2010) analyzed the 1972 vice presidential candidate Thomas 
Eagleton's revelation of his hospitalization for depression. Johnson (2010) applied rhetorical methods from ancient Greece and the research of Erving Goffman to Eagleton's disclosure of mental illness, claiming that the stigma of mental illness creates a disabling rhetorical effect that ultimately cost Eagleton his position as George McGovern's running mate.

Similar studies have examined how texts can rhetorically create a stigma of mental illness for a given culture. Stone (2018) studied how Mormon ideographs prevented Mormon churchgoers from perceiving mental illness as a medical disability. Stone (2018) also scrutinized how some church members used counter-cultural rhetoric to reframe the church's portrayal of mental illness in a way that approved of seeking medical help without surrendering their ideological beliefs. In addition, Glick and Applbaum (2010) used discourse analysis to examine the portrayal of mental illness in CNN's Special Investigations Unit. The researchers found that the program used a "semiotic reduction" to reinforce the cultural archetype of mental illness as a simple biological disease (Glick \& Applbaum, 2010). Of course, these examples differ from arguments surrounding mental illness in television drama, but they do exemplify how scholars have evaluated the rhetorical power of texts related to the topic.

\section{Rhetorical Analysis of Mental Illness in Literature}

In addition to general rhetorical research on mental illness, some scholars have narrowed their focused to the subject in literary fiction. Mathivanan and Soundararajan (2014) examined how the symbolic significance of the characters in Leo Tolstoy's The Death of Ivan Ilych establishes the author's argument regarding one's depression when confronted with imminent death. Storhoff (2004) found that John Okada's No-No Boy presents the novel's depressed protagonist, Ichiro, as someone who irrationally abstracts and catastrophizes his negative attitudes as one does when afflicted with a major depressive disorder. Karthikeyan (2013) 
employed a psychoanalytical study to the characters in D.H. Lawrence's Lady Chatterley's Lover, arguing that Lawrence draws connections between mental depression and the male view of a domestic lifestyle in romantic relationships.

Other scholars have focused on how the form of a novel creates an author's argument about coping with mental illness. Farkas (2016) applied a "text linguistics" rhetorical approach to William Faulkner's The Sound and the Fury, specifically the section narrated by the character of Benjy, whose mental deficiencies lead to the novel's most nonlinear (and arguably most confusing) stream-of-consciousness sequences. Farkas (2016) found that this relatively incoherent writing style paradoxically helps the reader make sense of mental illness by accurately portraying the scattered mental processes of someone with such a disorder. Vendler (2000) also examined the use of incoherent stylistic devices by focusing on Robert Lowell's poetry, arguing that such works about mental depression tend to avoid neat and accessible diction and sentence structure to portray the fragmented mind of someone suffering from a mental illness. Again, although these examples differ from the rhetorical strategies used in dramatic television, they indicate that fictional narratives in general can use such strategies to craft arguments related to one's experiences with mental illness.

\section{Rhetorical Analysis of Mental Illness in Film}

More closely aligned with this study's content is the existing body of rhetorical criticism in film. Although some might be hesitant to label films as rhetorical compared to literature or other, more "traditional" channels, others argue that film is a necessary platform to examine rhetorically. Behrens (1979) discusses the surprising lack of rhetorical criticism of film, claiming that because films try to influence an audience's attitudes and beliefs, they should be treated as both dramatic and rhetorical artifacts. However, despite this apparent lack of rhetorical research 
surrounding film, many scholars have evaluated prominent films through a rhetorical lens. Nicholls (2004) applied a series of psychoanalytic methods to Martin Scorsese's The Age of Innocence to determine its overall argument regarding masculinity and melancholia. Similarly, Grist (2007) used a Freudian/Lacanian framework to analyze Jake La Motta's masochistic desires in Scorsese's Raging Bull, concluding that the film presents a progressive (if not radical) position on the subjects of masculinity and masochism. Such examples do not necessarily involve clinical depression and/or mental illness, but they do exemplify the rhetorical aspect of film criticism and how it can excavate meaning regarding a character's psychological state.

Some researchers in film and rhetorical criticism have focused specifically on grief, trauma, and other symptoms related to certain mental illnesses. Hanich and Menninghaus (2017) applied a close textual analysis of a pivotal scene in Alejandro González Iñárritu's 21 Grams, arguing that formal characteristics of a "news of death" scene can instill potent, unique emotions within audiences. Anderson (2008) analyzed how the narrative structure of Tony Scott's Déjà $V u$ informed its references to traumatic events in the U.S., such as the $9 / 11$ terrorist attacks and Hurricane Katrina. Likewise, Angeli (2017) analyzed three significant moments in Kenneth Lonergan's Manchester by the Sea in which the film's protagonist, Lee Chandler, attempts to overcome a series of traumatic events. In each dramatic moment, Angeli (2017) draws upon Emerson, Barthes, and Derrida to determine Lonergan's perspective on numbness, immobility, and infidelity as they relate to the process of overcoming extreme emotional trauma. Of course, grief and trauma are not synonymous with mental illness, but these studies prove the possibility of studying a film's rhetorical argument regarding thoughts and emotions often associated with depression and other types of mental illnesses. 
Scholars have scrutinized the use of form in literary texts to reveal insights on mental illness, and such use of form has become important in the rhetorical study of films featuring mentally unstable characters. Gaedtke (2014) found that Deepa Mehta's Midnight Children relies on metaphors (among other rhetorical devices) to reveal its protagonist's struggle with paranoid schizophrenia. Novak (2019) examined how Christopher Nolan's Memento uses a reverse narrative structure and myriad references to classic Western films to shed light on the experience of anterograde amnesia. McMahon (2011) identified a rhetorical pattern in films such as What About Bob?, Running With Scissors, and A Beautiful Mind involving a therapist and patient, in which the films depict the patient having as much of an impact on the therapist's life as the therapist has on the patient. Another pattern critics have identified in films portraying characters with mental illnesses is how a film's narrative unfolds from the perspective of those characters. Blake (2017) found that films like Scorsese's Taxi Driver tell their stories through the subjective point of view of their protagonists in which these characters perceive themselves in an alternative universe separate from reality. Grist (2016) examined The Aviator, another of Scorsese's films, and how it uses color as a visually rhetorical strategy to reveal the true story of Howard Hughes coping with obsessive-compulsive disorder. A visual medium like film, then, possesses its own unique strategies to expand upon how characters (and, by extension, viewers) might cope with mental illness.

Some researchers have even narrowed their focus to how certain genres (notably the horror genre) use rhetorical strategies to convey meanings about mental illness. Marston (2015) critiqued Darren Aronofsky's Black Swan, finding that the film's presentation of the "shadow self" relates to its depiction of eating disorders and melancholia. Pheasant-Kelly (2012) applied Kristeva's theory of abjection to Scorsese's Shutter Island to determine how the film uses "abject 
spaces" in its mise-en-scène and cinematography. Pheasant-Kelly (2012) claims that the film's protagonist experiences a loss of identity because of the mental institution in which he is imprisoned. Riggs (2018) also used Kristeva's theory of abjection to analyze the horror films The Babadook and Lights Out. Riggs (2018) found that Kristeva's theory explains how the films invite the audience to view the mothers in each film as simultaneously appealing and revolting because of their mental illnesses.

Perhaps the reason scholars have placed more rhetorical attention on films than television is because of film's perceived literary quality compared to television. With the Third Golden Age of Television only existing in the previous few decades (Martin, 2014), cinephiles might be hesitant to apply the same level of scrutiny to the small screen. However, television arguably possesses a greater potential to change audience's understanding of mental illness. Television dramas by nature also provide more screen time than their cinematic counterparts, even when confined to one season. This structure allows viewers to develop parasocial relationships with characters and further understand their psychological wellbeing. A parasocial relationship refers to a continuous bond a viewer feels they have with a television character or some other persona they have not met in person (Horton \& Wohl, 1956). Some even develop parasocial relationships as a coping mechanism. Older viewers of television programs tend to create bonds with media characters in response to loneliness (Chory-Assad \& Yanen, 2005), and viewers suffering from traumatic experiences often rely on social surrogates to alleviate their symptoms (Gabriel, Read, Young, Bachrach, \& Troisi, 2017). Bonds between viewers and television characters can become so strong that these viewers might experience the same emotional distress as a real-life "breakup" when their favorite television series ends (Cohen, 2004). Because of viewers' potential to create parasocial relationships, television provides ample opportunity for viewers to 
further their understanding of depression and other mental illnesses. The formation of these relationships can help viewers better comprehend their peers' experiences with mental illness or even realize their own experiences with the concept compared to other, more traditional methods.

This long-form structure of dramatic television also allows writers to explore character actions and motivations with more intricate detail and nuance than if they were limited to a twohour span. It also gives character arcs room to expand and showcase the nonlinear nature of progress, especially as it relates to mental illness. A television series like The Sopranos keeps viewers guessing every week for years if therapy is effective in treating a depressed sociopath. It lingers in the "ordinary" moments of depression (i.e., Tony complaining that he could have bought a Ferrari with the money he has spent on half a decade of treatment) that a screenwriter would be eager to cut from the first draft of a tightly structured film script. These unique moments to television, as minute and trivial as they might seem to some scholars, indicate the necessity to view dramatic television with the same degree of rigor as a more "traditional" platform.

\section{Rhetorical Studies of Television Dramas}

Aside from this analysis within the horror genre, rhetorical studies of television dramas related to mental illness seem to be largely absent. However, the aforementioned studies indicate that high-concept "genre fiction" texts that might have been previously considered solely for their entertainment value are worth studying for their arguments related to mental illness. While studies combining the subjects of television and mental illness tend to focus on media effects and representations, rhetorical analyses of television programs tend to focus on themes unrelated to mental illness. For instance, Leverette (2004) examined how Larry David subverts traditional 
comedic tropes in his series Seinfeld and Curb Your Enthusiasm to present deviant and adolescent behavior. Sciullo (2019) analyzed the drama series Justified to argue that the show's use of visual rhetoric criticizes the Myth of the South by representing the Myth of the West. Sears (1995) scrutinized how the BBC series Crimewatch combines current events with elements of crime drama to establish its verisimilitude with audiences. The researchers specifically considered how the show's rhetorical devices simplify a series of complex news stories and confirm audience expectations (Sears, 1995). González (2019) dealt with the variety of transtextual layers in the drama series The Wire, determining that its rhetorical references to police procedurals, westerns, and Greek tragedies relate to Jonathan Franzen's concept of tragic realism. Still, although these studies interpret television comedies and dramas for their meaning related to the human condition, they do not seek to understand what these programs have to say about mental illness and the process of overcoming it. One of the few examples of rhetorical criticism of a television drama series that focuses on mental illness is Sheldon's (2019) analysis of the Netflix series The Haunting of Hill House. Similar to scholars examining horror films about mental illness, Sheldon (2019) applied Kristeva's theory of abjection to determine how the series' cinematography associates the depression of one of the characters with her family ties and other relationships. This study does attempt to understand how a television series challenges its viewers' perceptions of mental illness, but studies taking such a specific approach to the topic seem to be few and far between.

Similar to the present study, some scholars have considered how a television series might create an argument through its protagonist's denouement. Collins (2016), for instance, evaluated the series finale of Boardwalk Empire, in which the main character, Nucky Thompson, is forced to confront his guilt over allowing the predatory commodore of Atlantic City to seduce a 12- 
year-old girl. The series reveals this information several seasons earlier, but the choice to remind viewers of Nucky's actions from the beginning of his career, Collins (2016) argues, establishes the show's thesis that those in power will inherently exploit the most vulnerable members of a society. Dunst (2020) took a similar critical approach to the finale of the Netflix series BoJack Horseman. Dunst (2020) analyzed how the show's midseason finale initially offers a glimpse of hope for its titular protagonist before forcing him in the final episodes to reckon with his past misdeeds. Dunst (2020) argues that the show's strategic choice to punish the protagonist in the series finale represents a formal and cultural shift from the finales of dramas that initially dominated the Third Golden Age of Television. Unlike Mad Men and Breaking Bad, two shows that Dunst (2020) claims valorized their protagonists, BoJack Horseman continues to reference the lives BoJack has ruined, contributing to the show's argument that personal traumas should not excuse predatory behavior in Hollywood, even when that behavior has occurred in the distant past.

Although these analyses consider the impact a television drama's ending can have on its overall argument, they do not attempt to describe the argument's connection to the topic of mental illness. Of course, these aforementioned shows might not be inherently related to mental illness, but the existing literature on television dramas' character endings as a rhetorical strategy provides the basis for how this study's focus on the final season of The Sopranos crafts its argument on overcoming depression.

\section{Cultural and Generic Norms of the Gangster Genre}

What primarily separates The Sopranos from its contemporaries is not just its premise regarding mental illness, but its backdrop of the mafia / gangster genre. While the rhetorical portrayal of mental illness in television dramas might be relatively unexplored, several scholars 
have examined the generic conventions of the gangster in popular culture. Shadoian (1979) analyzed how gangster films from the 1930s depict the American gangster indulging in the luxuries of the mafia lifestyle only to find himself punished for his choices in the end. Dibeltulo (2014) considered how films like Scarface and Little Caesar contain frequent themes of family and Italian heritage. Cavallero (2004) evaluated the simultaneous American attraction to and revulsion from Italian characters in gangster films, claiming that the rhetorical use of these characters allows filmmakers to challenge American beliefs while also distancing themselves from Italian ideologies. Heffernan (2017) also evaluated the importance of ideology in gangster films, arguing that classic salvation stories and "slum plays" inspired the gangster regeneration cycle to include progressive ideologies in its narratives and themes. Larke-Walsh (2012) found in Abel Ferrara's The Funeral a contradiction of Italian American Mafia cultural mythologies that bolsters the film's presentation of masculinity.

Some researchers have looked specifically at iconic gangster films for their impact on the genre and American culture. Roberts (2006) explored themes related to the American Dream present in Howard Hawks' 1932 version of Scarface, claiming that the film owes much of its thematic content to F. Scott Fitzgerald's novel The Great Gatsby. Perhaps the most notable artifact for scholars of the gangster genre is Francis Ford Coppola's The Godfather. Little (2015) found that the film's reliance on images to appeal to audiences connects with how it questions authority's legitimacy. Freedman (2011) also examined The Godfather to discover themes related to primitive accumulation and globalization. O'Leary (2009) applied a rhetorical, psychoanalytic approach to the film, finding that the transformation of the film's protagonist, Michael Corleone, from an ordinary citizen to the leader of a criminal organization stems from his desire to fulfill unconscious desires. 
Several researchers have explored the structure and impact of notable works in the gangster genre. However, it seems no studies have combined a focus on conventions of the genre with an analysis of how the characters overcome a mental illness. This study, then, hopes to combine the rhetorical approach scholars have taken to understand mental illness in fiction to a text known largely for its use of conventions in the gangster genre.

\section{Existing Research on The Sopranos}

In addition to the existing research on notable works featuring Italian American characters involved in criminal organizations, some researchers have narrowed their focus to The Sopranos itself. In fact, scholars have applied a variety of critical lenses to The Sopranos. Some have focused on the presentation of gender issues in the series. Leone and Peek (2007) analyze how Tony Soprano's relationships with his wife Carmela, his mistresses, and his therapist Dr. Melfi challenge existing romantic myths. McCabe and Akass (2006) consider how Carmela's subservient role to Tony as a housewife reinforces certain feminist perspectives. Palmer-Mehta (2006) writes about the conflicting roles between Tony and his sister Janice and how Janice uses her womanhood to turn the matriarch of the family, Livia Soprano, against Tony. Santo (2002) even examines issues related to weight and body images from linguistic cues expressed throughout the series.

Researchers have considered portrayals of race in The Sopranos as well. Gibson (2006) examines the frequent racial epithets used by the main characters, and some critics have both defended and decried the series for its dependence on Italian American stereotypes to define the characters (Barreca, 2002). Considering scholars have analyzed everything about the show from its existential and nihilistic themes (Baker, 2004; Stoehr, 2004) to its evaluation of psychodynamic therapy (Flamini, 2002; Vincent, 2008) to its constant depictions of Italian food 
(Dunne, 2002), The Sopranos has proven to be a complex text worth studying from a variety of perspectives. However, despite the plethora of critical applications to the series, few (if any) have used a rhetorical approach to examine the show's ideas about overcoming depression. This study, as a result, expands on previous research to illuminate the show's treatment of the concept.

\section{Conclusion}

Ultimately, an abundance of literature regarding mental illness and mass media exists. It covers everything from the association between television-watching behaviors and possessing a mental illness to representations of mental illness on screen to the rhetorical analysis of the subject on television dramas. However, this final component is the least common of the subjects

covered in this literature review. Plenty of researchers have rhetorically examined how literature and film attempt to change audiences' understanding of mental illness, while others have applied similar lenses to television dramas, but few have combined these approaches to better comprehend the arguments regarding mental illness presented in television dramas. This study, as a result, applies a rhetorical approach to determine how The Sopranos attempts to persuade viewers about the nature of depression and the process of overcoming it. The following chapter consequently outlines the specific approach the study takes to identify the meanings regarding mental illness communicated by The Sopranos. 


\section{CHAPTER III: METHODS}

I debated several potential methods to use for this study. Everything from semiotics to psychoanalysis to analyzing the use of both a serialized and episodic structure in the final season of The Sopranos was fair game at some point. However, despite my indecisiveness in choosing a method, I did know that the ideal method would be the one that best helped answer my research questions regarding what the series has to say about the nature of depression and the process of overcoming it. I also knew I was fascinated by how the show's pilot raises the dramatic question of whether Tony will achieve that goal of overcoming his depression, with Tony lamenting to his therapist that the era of his idol Gary Cooper is over and that younger generations are pathetic for going to therapy and complaining about their problems. Because the series ends with Tony playing Journey’s “Don’t Stop Believin'” in a diner, I wanted to determine how Tony's character change (or lack thereof) throughout the series establishes the show's argument about depression, a thought process that lent itself to two primary methods.

The first, overarching method stemmed from the show's use of intertextual references that is evident in those two bookended moments that inspired this study. Tony's mention of Gary Cooper in the pilot and his choice to play a Journey song in the finale illustrate Tony's connection to the "real world" with which the viewer is familiar. Gary Cooper was a real American icon, and the use of "Don't Stop Believin"” in the finale is diegetic in that the source of the song exists in the show's universe, rather than just being used in the soundtrack. The characters are experiencing (and perhaps being affected by) the texts surrounding them. After taking an inductive look at the final season, I realized this pattern is prevalent throughout the season's nine episodes. Characters often quote song lyrics and seek out specific films and television shows to bond with one another, and crucial plot points frequently occur in tandem 
with these references. Therefore, to determine how this pattern establishes the show's argument related to depression, I applied an intertextual analysis as my initial method.

Derived from Bakhtin's claim that narratives are dialogues between past and present cultures, intertextual analysis scrutinizes how a given text alludes to other texts (Kaźmierczak, 2019). Kristeva (1986) argues that intertextual references are so ubiquitous that all texts are comprised of other quotations or sign systems in some form. Other scholars have distinguished between different types of intertextual references. A text might be adapting a previous narrative to a new form or attempting to invoke a sense of nostalgia in audiences by recycling imagery or ideas from older generations (D'Angelo, 2009). A text might also parody or satirize another text through its use of allusions (Ott \& Walter, 2000).

Therefore, to understand the purpose of the myriad intertextual references in the final season of The Sopranos, I first identified each of those references to collect my "sample" of data. I then created clusters for these references based on common themes among them. Some initial themes were related to the types of media in which characters in the final season indulge, whether it is films, television shows, or music. However, this type of grouping seemed too simple and reductive to make a compelling argument. Another theme that emerged was the final season's constant references to earlier moments in the series. Characters in the final season often refer back to their dialogue and actions from previous seasons, as if the series is trying to remind the viewer of previous events for reasons unrelated to the plot. The final season, as a result, is not just an amalgamation of classic and contemporary media artifacts - it is a synthesis of plot points, imagery, and character details from the entire series. With this lens in mind, broader intertextual themes that are more related to this study's research questions began to emerge. For instance, the show's references to previous seasons tend to relate to Tony's inability to escape 
the depression his parents instilled in him as a child, while the final season's imagery alluding to religious and spiritual ideas often reveal how the characters dread the irreversible nature of death. Complementing these allusions is the show's references to diegetic media (Gary Cooper, Journey, etc.), which perhaps act as a commentary on how individuals from different generations use popular media to cope with depression. The final season of The Sopranos therefore uses its intertextuality to present depression in a variety of manifestations and argue for how those suffering from it attempt to cope with and potentially overcome it.

This strategy, even with its broader focus on different forms of depression, still seemed a bit limiting in its ability to connect the show's intertextuality to the show's overall argument. In fact, an intertextual analysis seemed inherently incapable of answering my research questions. Even the most original and insightful ways of clustering the final season's intertextual references accomplished little more than identifying patterns and resembling a post on a Sopranos subreddit page titled, "Hey, Look What I Found!" Thus, this analysis of The Sopranos relies on a secondary framework using Burkean frames.

Kenneth Burke's poetic frames, specifically those of acceptance and rejection, essentially help identify how individuals in a text "frame" their experiences and act accordingly. Frames of acceptance generally refer to a character's recognition that they cannot change their situation and learn to live with it, while frames of rejection motivate the character to enact change (Burke, 1984). A "tragic" frame of acceptance, for instance, might explain how a character undergoing treatment for a mental illness accepts the irreversible status of the illness and learns to cope with it (Burke, 1984). "Tragedy" in this case does not necessarily mean "sad" or "depressing," but it depicts characters resigning themselves to their limitations, forcing them to endure the consequences of that acceptance. A resignation like this might even be liberating for the 
individual, a possibility this study explores in its analysis of the dramatic question posed in the final season of The Sopranos.

This use of Burkean frames interprets meanings from the character's perspective, but these frames could be applied from a different point of view. A "grotesque" frame of rejection in a dramatic narrative, for instance, might invite the audience to view a character as a horrifying contradiction, one that repulses them and attempts to convince them to reject the character's flaws to avoid the same harrowing fate (Burke, 1984). This study examines a variety of these frames in the final season of The Sopranos and argues that as a thematically complex text, the series leaves room for several interpretations of the characters' (and the show's) frames of depression.

Although it seems no studies have applied Burkean frames to the topic of depression, many have used the method in variety of other texts. For instance, Appel (1997) noted a rhetorical shift in how Dr. Martin Luther King, Jr. framed his opponents during the civil rights movement, finding that King transitioned from a primarily comic frame that portrayed these opponents as ignorant and misinformed to a more tragic frame that more severely condemned them for their behavior. Ott and Aoki (2002) applied a similar analysis to media coverage of the murder of Matthew Shepard, a University of Wyoming student who was beaten to death for being gay. The researchers found that media outlets often portrayed the event using a tragic frame to provide a scapegoat and alleviate public guilt about contemporary hate crimes (Ott \& Aoki, 2002). As another application of Burkean frames to social justice issues, Christiansen and Hanson (1996) found that the AIDS Coalition to Unleash Power (ACT UP) used the comic frame to suggest how marginalized and oppressed groups respond to the scapegoating process. 
More related to this study, some researchers have applied Burkean frames to popular television programs. Kanol (2020) contrasted Jon Stewart's comic framing of contemporary news events with Glenn Beck's tragic framing of similar circumstances. Other scholars have focused on original television narratives in their use of Burkean frames. Biebel (2010), for instance, analyzed the first season of the American version of The Office, using the comic frame to illuminate the show's views on financial necessity in the U.S. and the mundane nature of the corporate workplace. Likewise, Lewis (2002) applied the comic frame to The Simpsons to suggest that the series satirizes the religious and hypocritical elements of American culture without ridiculing the foundation of religion in the country. Lewis and Molloy (2015) also used Burkean frames to examine arguments of religion in The Big Bang Theory, finding that the series combines frames of satire, burlesque, and intertextual references to determine the show's argument about religious hypocrisy. The researchers cluster their analysis by focusing on each of the show's main characters and their varying degrees of piety (Lewis \& Molloy, 2015). These examples therefore demonstrate the applicability of Burkean frames to television narratives and their potential to excavate their meaning on a critical subject. These methods, however, have ostensibly not been applied to television dramas focusing on mental illness, something this study attempts to accomplish with its combination of an intertextual and Burkean framework.

Because this study used two general methods in its analysis, I established a hierarchy and order between the two before applying them to the final season of The Sopranos. I started with the intertextual framework as the "secondary" method by reviewing the final season for its intertextual references, such as those related to both popular culture and certain moments from earlier in the series. For the former, I noted moments when characters engage with specific forms of media, including songs, films, and television programs (as opposed to soundtrack music that 
typically plays at the end of each episode). For the latter, I considered details from the final season that specifically resembled moments from earlier seasons that seemed too similar to be coincidental. The visual framing of shots, lines of dialogue, or character actions mirroring those from previous seasons initially counted as "data." This collection of references was then narrowed down to moments related to some aspect of my research questions about mental illness before being clustered into those different aspects. Some character details or diegetic references to media platforms were clearly intertextual but simply did not coincide with this study's topic and were discarded from the sample. The resulting data helped answer the first part of my research questions concerning how the final season uses its intertextuality to present depression as a consequence of familial, existential, and technologically mediated communication. I then applied Burkean frames to the data as my "primary" method to determine the final season's argument regarding how one might overcome their depression in each of those forms. In some cases, characters (through their overall arcs and most pivotal decisions) appear to either accept or reject the situations contributing to their mental illness. Viewed through a tragic frame, Tony (among other characters) tends to accept his limitations as someone with a mental illness and learn to cope with the "status quo" of living with depression. At times, the series itself appears to depict depression through a grotesque frame to argue that characters like Tony will ultimately remain miserable their entire lives, urging its viewers to reject the ways these characters attempt to treat their mental illnesses.

The following chapter describes these results in more detail. It addresses each major type of depression posed by this study's research questions, starting with depression resulting from one's family background and ending with the relationship between depression and one's use of various media devices. Each section begins with the findings from the intertextual analysis and 
describes how the final season's intertextuality argues that depression can assume the form detailed in that section. Each section then applies Burkean frames to those forms of depression to determine the final season's claims regarding how individuals might, successfully or not, attempt to overcome them. 


\section{CHAPTER IV: ANALYSIS}

Through an intertextual and Burkean framework, this chapter analyzes the major research questions posed at the beginning of the study. It attempts to understand the overall arguments in the final season of The Sopranos regarding the nature of depression and how someone might be able to overcome its symptoms. To evaluate the major components of this study, this chapter covers three primary sections: depression resulting from one's family background, depression resulting from an existential crisis, and the relationship between depression and one's use of contemporary media platforms (television programs, popular music, etc.). Each of these sections begins with a general overview of how the final season of The Sopranos uses its intertextuality to portray the type of depression discussed in that section. It then transitions to how the lens of Burkean frames might explain how the characters in The Sopranos accept or reject their situation involving their mental illness and how the series itself is framing that type of depression as something to be accepted or rejected. Each section also offers different perspectives on each component of the final season's argument. This dichotomy of perspectives might even appear contradictory at times - the methods of intertextuality and Burkean frames reveal character moments of both resilience and resignation. This study consequently elaborates on how this ambiguity of The Sopranos (along with this analysis) can expand upon audience perceptions of mental illness.

\section{Depression Resulting from One's Family Background}

One of the primary ways the final season of The Sopranos uses intertextual references to craft its argument on depression is through its illustration of how depression is created and maintained through one's family connections. For instance, the final season depicts Tony (among other main characters) struggling to understand how his depression stems from his upbringing in 
a mafia household as he tries to salvage the connections that still exist in his current family.

Much of the final season's intertextuality in this regard refers to moments in previous seasons involving the Soprano family's history of mental illness and emotional trauma.

\section{Characters "Becoming" Their Parents}

Many key examples of the final season's highlight of depression as a generational concern suggest that individuals can carry depressive symptoms similar to their parents. One such moment occurs after the suicide attempt of Tony's son AJ in the episode "The Second Coming" (Winter, 2007). AJ's therapist arranges a family therapy session between AJ and his parents (Tony and Carmela), and they discuss potential causes of the attempt. AJ mentions a speech his grandmother (Livia) gave him toward the end of her life when she was in the hospital, a scene that plays out in the season two episode "D-Girl" (Kessler, 2000). Livia tells AJ in this monologue that life is "all a big nothing" and that everyone will ultimately "let you down" when you eventually "die in your own arms." AJ tells his parents and his therapist that this nihilistic worldview has haunted him ever since (Winter, 2007). Tony dismisses AJ's expression of Livia's monologue as nothing extraordinary - it was just the way his mother would always talk. However, this scene references other moments of Livia's nihilism that indicate Tony was affected similarly as a child. The season two finale "Funhouse" shows Tony waking up after a series of nightmares crying and repeating Livia's phrase of "it's all a big nothing" (Chase \& Kessler, 2000). At the end of that episode, his therapist Dr. Melfi warns him of his underlying psychological wounds stemming from his mother's inability to express affection or even experience joy herself. Thus, while Tony might not admit his long-term struggle with a bleak worldview, he clearly suffers from emotional baggage that affects his own son, and it is the 
show's reference to its earlier depiction of mental illness that presents the topic as something that might originate and remain intact as a result of one's family ties.

Tony not only suffers from Livia's lack of affection long after her death, but he mimics her same parental qualities that likely contributed to her toxic relationship with her son. Tony's resemblance of these qualities is arguably the most prominent in the show's final season. The first episode of the final season, "Soprano Home Movies," follows Tony and Carmela joining Tony's sister Janice and her husband Bobby at their lake house as Tony escapes the police's investigation of a weapons charge against him (Frolov, Schneider, Chase, \& Weiner, 2007). The four of them seem to be enjoying their evening outdoors when Janice compliments Tony on all the progress he has made over the years. When Tony questions what she means and becomes irritated that she is implying he was a "problem child" in their youth, Janice tells him it was a compliment and to avoid becoming defensive. Janice, Bobby, and Carmela return to admiring the nature around the lake house when Tony looks at Janice and Bobby's young daughter playing with the family's housekeeper. Tony then recites a news story about a child who fell into a swimming pool and currently suffers from permanent brain damage. Tony seemingly tells this story as revenge for Janice's snide comment directed toward him, as he knows the morbidity of the story would upset anyone, let alone a couple with a young child of their own.

Likewise, Tony's mother was known for such bleak utterances, in addition to her nihilistic speech to AJ. In the show's first season episode "Meadowlands," Tony tries to convince Livia to attend a field trip to New York City with the other members of her retirement community (Cahill \& Patterson, 1999). Livia responds by mentioning all the mothers who throw their babies out of the skyscrapers in the city, after which Tony rolls his eyes and says, "Always with the babies out the windows" (Cahill \& Patterson, 1999). Livia is upset with Tony in this 
scene for placing her in the retirement community, and her recounting of this story is presumably a spiteful move against Tony. Given Tony's reaction, this was not the first time Livia mentioned such morbid stories. Perhaps, though, Livia is not acting out of spite in any of these cases.

Perhaps she simply suffers from a chemical imbalance that prevents her from enjoying moments with her family and forces her to dwell on the horrors of the world. Tony might be displaying the same phenomenon at the lake house. In either case, the show references these earlier moments in the final season to present depression as an experience that permeates throughout one's lineage, regardless of whether it does so via nature or nurture. Consciously or not, children of emotionally abusive parents are ultimately, according to this aspect of The Sopranos, doomed to inherit their parents' morbid and violent nature.

Tony's sadistic actions, like his mother's, might stem from something more broadly than a source of petty revenge. Instead, they might result from his jealousy of those without clinical depression. Another episode of the final season, "Remember When," also follows Tony briefly escaping New Jersey because of an investigation, this time as a result of Tony's first murder that his father forced him to commit when Tony was in his early 20 s and that cemented him into the family’s criminal organization (Winter, 2007). Tony travels to Florida with his oldest associate Paulie Gualtieri, who uses the opportunity to recount a plethora of stories about Tony's father (commonly referred to as "Johnny Boy," his nickname in the crime family), partly because he and Paulie worked together for years and partly because the entire trip is spawned from the actions of Tony's father. Paulie seems to have fond memories of Johnny Boy, but Tony appears relatively reserved as he listens to Paulie's stories, possibly because Tony is reminded of the reason he has become trapped in a lifestyle that has bought him more misery than luxury. At the end of their trip, Tony learns that the investigation against him is over and that he and Paulie are 
safe for the time being. Tony is briefly relieved before walking out onto the balcony of his hotel room and watching the palm trees sway in the wind near the shore. His smile quickly starts to fade as his momentary bliss ends - he is back to his ordinary criminal life, the one his father condemned him to decades ago.

While not a direct intertextual reference to a specific moment in the series, this moment does refer to Melfi's consistent assertion that Tony's mother was never able to experience joy. More closely resembling these references to Tony's mother is Tony's reaction after his smile fades when watching the ocean. He looks to Paulie (who has yet to learn that the investigation is over) to see him laughing hysterically while watching Three's Company. Tony consequently invites Paulie to join him on his boat the next day and considers murdering him the same way he murdered his former associate "Big Pussy" Bonpensiero after discovering he was an FBI informant. Tony's rage toward Paulie arguably stems from Paulie's ability to enjoy the "little things" in life both Tony and his mother were incapable of experiencing. Even when his comfort and livelihood is at stake, Paulie can benefit from simple pleasures like watching television and going to the beach. Again, although this moment is not a literal reference to specific moments in the series, it does refer to the show's frequently established narrative of Livia's nihilism and how she instilled her worldview in her son. For instance, the final scene in the first season finale of The Sopranos titled "I Dream of Jeannie Cusamano" depicts Tony having dinner with his wife and children after surviving the assassination attempt indirectly ordered by Livia (Chase, 1999). He tells his children that one day they will have families of their own and will learn that the "little things in life" are what matter most. The sequence between Tony and Paulie in the final season, then, indirectly references this narrative to imply that depression is a generational conflict by which individuals can be affected long after their parents have died. Tony might have 
been able to enjoy those moments at the time, but years later, he appears to have acquired the most distressing traits that made his mother incapable of being happy. It is an undoubtedly bleak philosophy, but one that might resonate with viewers without such an overtly violent background. We might not be gangsters wanting to kill our closest friends, but we likely understand the concept of displacing repressed rage from our childhood on our current relationships, and this intertextual sequence in The Sopranos informs us of how easily we are subconsciously tempted to act on that rage.

Characters in The Sopranos occasionally reference the history of mental illness in the Soprano family, with some even considering it a curse. The series uses these instances of dialogue to intertextually orient the viewer to the long-term struggle with mental illness some families face. For instance, AJ has his first panic attack in front of his parents in the show's third season episode "Army of One" (Chase \& Konner, 2001). Tony then tells Dr. Melfi that AJ has been afflicted with the "cursed Soprano gene," claiming that his great grandfather had a panic attack while driving a donkey cart in Avelino (Chase \& Konner, 2001). After AJ's suicide attempt in "The Second Coming," Carmela blames Tony's family history for AJ's depression, referencing the donkey cart incident and telling him that "he didn't get it from my family" (Winter, 2007). Although Tony becomes enraged and breaks an expensive watch he recently bought for Carmela, he seems to believe in the "family curse" himself, reiterating his concerns to Melfi in the final season episode "Walk Like a Man," telling her that his "putrid rotten fucking genes" have infected AJ (Winter, 2007). The characters' frequent references to mental illness in their family history serves not simply to remind the viewers of key character details, but to suggest that those narratives instilled in them from their families permeates throughout their entire adult life. 
The final season of The Sopranos also uses more figurative references to the titular family's history of mental illness to solidify its argument about depression. In the fourth season episode "The Strong, Silent Type," Tony cries in Melfi's office about the murder of a racehorse in which he had recently invested (Chase, Winter, Green, \& Burgess, 2002). He asks Melfi at the end of the session, "Why can't we all just get along?" (a quote he attributes to the "Reverend Rodney King, Jr.”). This malapropism resurfaces in the final season during AJ's struggle with depression. In the final season episode "Kennedy and Heidi," when AJ seems to be making progress in his mental health after breaking up with his fiancé, he witnesses a racially motivated attack on a Somali boy, after which he cries in his own therapist's office and mentions the same quote (Weiner \& Chase, 2007). While AJ's use of the same line might simply be a coincidence, the similarities extend beyond the language. Tony's use of the quote was in response to a personal event that he then catastrophized to more widespread issues, a type of cognitive distortion often linked to depressive disorders ("How to Stop Catastrophizing," 2020). Likewise, the initial source of AJ's depression was the dissolution of his relationship with his fiancé, but his perception of the racial violence causes him to obsess over everything from the IsraeliPalestinian conflict to the war in Iraq during his next therapy session (Weiner \& Chase, 2007). Thus, what appears to be a simple "Easter egg" of an intertextual reference on the surface is actually an avenue for the series to explore the genetic relationship between depression and various family members. It tells us that symptoms of depression like catastrophizing can manifest themselves in minute, often unnoticeable ways and that children do not need to attempt (or even threaten) suicide for us to notice they have inherited these types of traits. Perhaps this intertextual sequence urges viewers to further scrutinize these characteristics in their loved ones (or even themselves) to identify the warning signs of severe depression. One of the reasons we 
fail to prevent suicidal behavior in our families, The Sopranos seems to suggest, is that we focus too heavily on the overt "red flags" of depression compared to subtle linguistic cues revealing one's mental illness.

The Sopranos also explores these types of intertextual connections with depression in more metaphorical ways throughout the series. During Tony's therapy session about the racehorse in "The Strong, Silent Type," Melfi tells Tony that the last time he was so emotional during a session was related to a family of ducks living in his swimming pool (Chase, Winter, Green, \& Burgess, 2002). This instance plays out in the pilot, in which Tony jumps into the pool to play with the ducks, but then has his first on-screen panic attack when the ducks leave (Chase, 1999). At the end of the episode, Melfi helps Tony realize the ducks serve as a metaphor to Tony for his own family and that his subsequent panic attack reveals his subconscious fear of losing them. AJ's suicide attempt in the final season occurs in the same pool, which Tony once again jumps in, this time to save a literal family member struggling with the same mental illness as his father (Winter, 2007). The Sopranos consequently relies on the swimming pool as an intertextual metaphor permeating throughout the series to illustrate parents' potential cause of (and inability to treat) their kin's depressive symptoms.

The ducks also serve a more mythological intertextual purpose. Native American legends often depict ducks as gullible animals tricked into being prey for foxes and coyotes ("Native American Duck Mythology,” 2015). Because Melfi informs Tony that his anxiety while watching the ducks represents his fear of losing his family, The Sopranos establishes the concept of family as a fragile entity from the first episode of the series. Our families are always vulnerable to predators, even if they are not involved in the mafia. Tony even understands that the greatest threat to his family might not be assassination attempts from rival gangsters. Tony 
tells Melfi in the pilot he does not know the source of his fear - he knows he is terrified of losing his family, but his mental illness might pose an equally (if not more) powerful challenge to supporting his wife and children. In this therapy session, Tony also describes to Melfi his recent dream involving a duck placing Tony's penis in its beak before flying away with it (Chase, 1999). Perhaps, then, Tony "losing his family" does not necessarily refer to them being killed by rival mafia members but to them no longer trusting him as a masculine father figure, as it is the representation of Tony's family that emasculates him in his dream. The sequence might even be a direct response to the Thai saying, "I better get home or the ducks will have something to eat," referring to the possibility that a woman might sever her husband's penis if she discovers he is committing adultery (Scicurious, 2013). Tony is no stranger to adultery, and he even hallucinates in the first season that Carmela threatens to "cut his dick off" (Green \& Burgess, 1999). Oddly enough, though, because the duck (not Carmela in response to his philandering) removes Tony's penis in his dream, Tony seems more afraid of his family abandoning him for his failure to maintain an alpha male status than for his numerous amoral actions. It is a fear that should resonate with all viewers - even if we remain committed to our families in every way (financially, emotionally, etc.), they might still reject us for qualities we are unable to display, a prospect that becomes increasingly likely with the onset of certain mental illnesses.

If the first season of The Sopranos uses ducks to symbolize a family's fragility, the final season reveals the most dangerous and insidious predators (the "coyotes" and "foxes") targeting the core of family relationships. After Tony murders Christopher and escapes to Las Vegas, his associates are struggling to find a drop-off location for a large quantity of asbestos. When Tony fails to respond to these associates, they dump the asbestos in a nearby lake while ducks can be heard quacking in the background (Weiner \& Chase, 2007). As an intertextual reference to the 
pilot, the ducks arguably symbolize Tony's "poisoning" of his own family because of his inability to help them when they need it - Tony ignored his nephew's addiction before killing him himself, and he flees to Las Vegas to satisfy his hedonistic pursuits when his family members (some of whom are severely depressed themselves) are coping with the sudden and violent death of a close family member. Through this intertextual sequence, The Sopranos appears to jettison the stereotype that those with a mental illness are more empathetic to those suffering from similar ailments. Someone suffering from depression would theoretically be better equipped at supporting other depressed individuals because they understand the symptoms themselves. Tony's actions, however, indicate the opposite - his depression has left him desensitized to the struggles his closest acquaintances face. Even if he has mitigated the symptoms that ailed him in the pilot (or perhaps because of that mitigation), Tony has "infected" his family the way the ducks infect the lake, but not necessarily because of the genetic predisposition he laments to Melfi. AJ continues to suffer from depression as Tony escapes to Las Vegas and neglects his responsibilities as a father. The real "poison" behind families with a history of depression is not their biological connection to mental illness, but their refusal to comfort each other and express empathy about a subject with which they are uniquely familiar.

\section{Characters' Attempts to "Escape" Their Parents}

Another primary purpose of the final season's intertextual references to its previously established narratives is to depict characters trying to escape the depressive symptoms their parents instilled in them at a young age. Some of these moments exist as brief asides unrelated to the final season's major plot points, while others drive the overall narrative of the season. For instance, not long after Tony tells the story of the injured child at Bobby and Janice's lake house in "Soprano Home Movies," Tony observes the housekeeper singing the traditional children's 
song "Five Little Ducks" to Bobby and Janice's daughter (Frolov, Schneider, Chase, \& Weiner, 2007). Tony grimaces as he watches the two of them in disgust, with the ducks metaphor presumably reminding him of the compassion his mother failed to provide him. Another such moment occurs after Tony murders his Christopher for relapsing in his heroin addiction. Christopher's wife (and now widow) is grieving at the Soprano house when she begins breastfeeding her child. It is in that instance Tony impulsively flies to Las Vegas (Weiner \& Chase, 2007). The series establishes the breastfeeding motif toward the end of the first season, when Tony slowly realizes his mother indirectly arranged his assassination attempt (Chase, 1999). During this point in the series, Tony has taken an excessive amount of medication and hallucinates a woman breastfeeding her son. Melfi helps Tony discover that the child represents Tony and his desire for a loving mother when he is subconsciously aware of Livia's murderous intentions. Therefore, after murdering Christopher and observing Kelly breastfeeding her son, Tony is reminded of his mother's actions and subdues the resurfacing emotional trauma by traveling to Las Vegas. While this reference, like AJ and Tony's similar dialogue in their therapy sessions, might be a coincidence, the insight this relatively brief intertextual moment provides for its characters seems to contribute to the final season's theme of individuals with a mental illness trying to escape their parents' abusive actions.

Tony's gambling pursuits also serve an intertextual purpose similar to the aforementioned examples, as they relate to how his father forced him into the family's criminal organization. The third season episode "Fortunate Son" reveals that as a child, Tony witnessed his father sever the finger of a pork store owner unable to pay his gambling debts (Kessler, 2001). Johnny Boy then assumes control of the store (a task Tony acquires as an adult) and brings a fresh cut of meat home to the family. Johnny Boy tells Tony before dinner that a man always honors his debts. 
Johnny Boy and Livia subsequently start to have sex at the dinner table, with Livia having been aroused at the prospect of her husband literally "bringing home the bacon" and providing for the family. Tony then has his first panic attack watching these events occur. However, in the final season episode "Chasing It," Tony develops a gambling addiction and largely refuses to pay his debts to some of his closest friends (Weiner, 2007), perhaps as a subconscious rebellion against the man who forced him into a lifestyle that has exacerbated his depression. At this point in the series, Tony has recently recovered from a coma that resulted from a gunshot wound. He tells his family "every day's a gift" when he recovers. In the sixth season episode "Live Free or Die," Tony settles back into his criminal lifestyle that is mundane at best and terrifying at worst (the kind of existential dread that spawned his initial entrance into therapy), and he tells Melfi a modified version of his new mantra: "every day's a gift, but why's it gotta be a pair of socks?" (Chase, Winter, Green, \& Burgess, 2006). The final season's introduction of Tony's gambling addiction serves not just to highlight Tony's literal attempt to escape the lifestyle that exacerbated his depression, but to illustrate how Tony seeks to distance himself from the ways his parents contributed to his incessant misery.

Arguably the most prominent intertextual reference relating to Tony's attempt to rebel against his father exists in the final season's subplot of Christopher producing a horror film. Entitled Cleaver and depicted in the episode "Stage 5," the film follows a man who is resurrected and kills the men who murdered him with a cleaver (Winter, 2007). The film likely reminds Tony of the cleaver his father used to mutilate the pork store owner who failed to pay his debts. In fact, one of the fictitious film's key characters closely resembles (and negatively portrays) Tony. After attending the film's premiere, Tony cries in Melfi's office and expresses his sorrow that his surrogate son resents him (Winter, 2007), a disposition Tony presumably possesses 
because of his attitude toward his own father. This parallel continues when Tony murders Christopher, as Christopher is wearing a hat with the Cleaver logo on it when Tony suffocates him. Tony then throws his Cleaver mug out his kitchen window the next morning, one of many actions relating to Tony's rebellion against Johnny Boy (Weiner \& Chase, 2007). One popular fan theory argues that Tony murders Christopher to vicariously murder his own father ("Tony's Vicarious Patricide," 2009). The theory claims that when Tony sees the empty car seat in Christopher's backseat before suffocating him, he identifies with Christopher's child (the same way he identified with the child in his hallucination about his mother) and murders Christopher in an eruption of his repressed rage against Johnny Boy. Of course, this theory is mere speculation, but the intertextual cues invite the viewer to consider the ways in which individuals attempt to reject their parents' abusive behaviors well into their adulthood.

Similar to how The Sopranos depicts characters assuming qualities of their parents when they reach adulthood, the series also uses an intertextual framework to demonstrate how individuals with a mental illness can be paradoxically unable to help their children (both biological and surrogate) endure a mental illness of their own. For instance, during AJ's intervention after his suicide attempt, AJ blames his mother for his depression, after which Tony says "poor you" and mocks AJ for attributing his depression to his upbringing (Winter, 2007). Livia was notorious for using the phrase "poor you" to belittle those around her (including her children) and elicit sympathy from them. In fact, in the third season episode, "Amour Fou," Tony has an affair with a woman with similar narcissistic tendencies, and it is when she recites the same phrase to Tony that he realizes the long-term effects Livia has had on him (Chase \& Renzulli, 2001). However, Tony seems to adopt the same self-centered attitude when attending his own son's intervention in the final season. 
This pattern continues at the end of the episode when Tony visits AJ in the mental hospital. He brings him a pizza, but the receptionist informs him of the institution's policy against bringing food to the patients (Winter, 2007). Tony then continues inside without it. It is a relatively minor detail, but an intertextual reference nevertheless. In the show's second season episode "From Where to Eternity," AJ drops a plate of food in the kitchen, and Tony angrily laments that his male heir is someone as clumsy as AJ (Imperioli, 2000). Later, Tony apologizes by bringing a pizza up to AJ's room, and AJ seems to accept the apology. Tony's failure to bring the pizza to AJ in the final season could symbolize Tony's inability to compensate for his lack of empathy for others' depression. He might have been able to buy his son's affection with food before AJ was severely depressed, but now that AJ's mental health has worsened, Tony is unprepared and underqualified to comfort someone despite struggling with the same issue himself. Perhaps, then, the series incorporates these references in the final season to not only illustrate the cycle of emotional abuse in families with a history of mental illness, but to also highlight how those with depression can, under certain circumstances, become desensitized to the issue and remain unable to help their own children.

\section{Characters and their Surrogate Children}

The final season uses similar methods to present characters incapable of showing empathy for their "surrogate" children or individuals with whom the main characters have general parental connections and responsibilities. The first episode in the final season to address AJ's severe depression is titled "Walk Like a Man" (Winter, 2007), a reference to a song by The Four Seasons and a parallel to Tony's oversimplified remedies to men struggling with depression. The episode's primary plotline, however, is related to Christopher, Tony's nephew and in many ways his surrogate son. At this point in the series, Christopher has recently become 
sober after years of battling alcoholism, a problem his father struggled with his entire life. He attends a barbecue with Tony, and Tony begins criticizing Christopher for how he is cooking the steaks on the grill (a possible reference to Tony's repressed rage toward his own father). The conversation shifts to Tony's irritation that Christopher no longer drinks with the rest of the crew, to which Christopher replies that alcoholism is an illness, one he inherited from his father and that Tony of all people should understand after spending years in therapy. Tony dismisses the comparison and claims that overcoming alcoholism is as simple as having willpower (Winter, 2007). This simple reference consequently seems to highlight the show's argument that an individual's desensitization to others' mental illness extends beyond one's immediate family and could affect those with illnesses other than depression, such as addiction and alcoholism.

Another primary way the show uses intertextual references to present mental illness as a generational concern affecting more than one's immediate family members is through Tony's gradual descent into inheriting his mother's apathetic traits. When Tony survives his gunshotinduced coma, he sees an Ojibwe saying posted on the wall in the emergency room saying, "Sometimes I go about in pity for myself, and all the while, a great wind carries me across the sky." He often recites this saying as a mantra to remind himself of his philosophy that "every day is a gift" and that we should "enjoy the little things." However, he begins to reference this saying to express his lack of sympathy to other people's problems, reflecting Livia's "poor you" attitude. In the sixth season episode "The Fleshy Part of the Thigh," when Paulie expresses his concern that the woman who raised him was not his biological mother, Tony tells him, "you go about in pity for yourself' and that other people suffer from far worse (Frolov \& Schneider, 2006). In the final season, Tony refuses to help the son of his former associate Vito after Vito is killed, reciting the same phrase he told Paulie (Weiner, 2007). Thus, perhaps the use of this 
reference signifies the final season's argument that we can be initially inspired to help others overcome personal difficulties similar to those we face, but we are prone to becoming insensitive and self-serving as we start to resemble our parents' behavior from years ago.

\section{Accepting and Rejecting One's Family Background}

The final season's myriad intertextual references regarding the relationship between depression and one's family connections raise a variety of questions, but it is the character arcs that solidify the final season's argument about how one can overcome their depression. One perspective the show appears to offer (using the Burkean frames of acceptance and rejection) is that individuals achieve some form of tranquility when they accept the irreversible nature of their depression as it relates to their families. The final season presents this type of acceptance in several different contexts. AJ, for instance, struggles to identify a steady career path after leaving the mental hospital. He considers everything from being a CIA agent to joining the military to being Donald Trump's personal pilot. But when his parents pressure him to find a job he is qualified for, he says he is clinically depressed and that his disability prevents him from doing so. He seems content to avoid finding a new job, an attitude that eventually works in his favor as Tony uses his connections to get $\mathrm{AJ}$ a script reading job for a film production company (Chase, 2007). AJ accepts that his depression instilled in him from his parents (whether it was through genetics or his parents' inability to show affection) will always affect him to some degree, yet he still succeeds in spite of it, albeit through his fortunate association with the leader of a criminal organization. AJ's fleeting interests in foreign affairs could blossom into a full-time career if it were not for his resignation to the limitations of his mental illness. From the perspective of this 
tragic frame, the final season argues that a blind acceptance of our mental illness is what limits our creative and intellectual potential, regardless of our familial history of mental illness.

A tragic frame also informs the way Tony learns to cope with his depression through accepting the constant role his mother's worldview plays in his life. Between Tony's mention of the injured child at the lake house and his contemplation of murdering Paulie, the final season raises the dramatic question of whether Tony can reverse the harmful effects his mother's ghost still weighs on him. In some ways, the answer arrives in the episode where he murders Christopher. Tony not only gets away with murdering his surrogate son (his closest associates and family members believe his lie that Christopher's death was an accident), but he is momentarily rewarded for it. By fleeing to Las Vegas, having sex with one of Christopher's former girlfriends, and winning several consecutive rounds of roulette, Tony shouts his infamous "I get it" line as if he finally understands his mother's nihilism after years of struggling with depression. Perhaps he believes she is right - the universe must be a "big nothing" if it rewards him for getting away with murder. In fact, the second half of Livia's philosophy was that "you die in your own arms." The camera frames Tony at the end of the episode crying with his arms behind his head watching the sunrise (Weiner \& Chase, 2007). Between years in therapy and several near-death experiences, Tony has spent his entire life reflecting on the nature of his depression and the possibility of treating something that was ingrained in him from his childhood. And yet, despite his years of self-reflection, he still ends up embracing his mother's nihilistic philosophy, further revealing the familial cycle of emotional dread implied in the scenes at the lake house and at the beach with Paulie.

However, Tony's acceptance of his mother's philosophy could also be viewed through a heroic frame. Burke (1984) argues that an “epic” within a heroic frame magnifies the hero's role 
in overcoming great odds and sacrificing something for the good of the group. Although Tony does not destroy the Death Star or the One Ring like Luke Skywalker or Frodo Baggins, he does appear to overcome his depressive symptoms by embracing his inability to distance himself from his mother's bleak worldview. Tony knows his mother's ghost will always haunt him, but by accepting the reality of her constant presence and that the universe is too random and chaotic to mitigate the suffering of those with a mental illness, he might ironically be able to benefit from it. The "tragedy" of Tony's acceptance, then, might not be much of a tragedy at all when it allows him to treat his depression.

These same intertextual references to Tony's mother, though, also subvert the sacrificial elements of Burke's heroic frame. Rather than sacrificing his need to self-actualize to serve his family, Tony neglects his family in their time of suffering to indulge in his own hedonistic desires. And yet, even as the asbestos poisons the ducks as a parallel to Tony's family, Tony still reaches an epiphany that momentarily benefits his mental health. The subversion of the heroic frame, then, reveals a crucial component of this sequence's argument - perhaps we need to be selfish to conquer our struggles with mental health. When depression prevents us from accomplishing the most mundane daily tasks, we cannot be expected to comfort others struggling with the same condition. If we are barely able to help ourselves, we might as well search for any victories we can find, even if they come at the expense of those we love most.

The final season's framing of Tony's acceptance of his mental illness as a family concern is merely one reading of the show's philosophy of depression. The ambiguity in The Sopranos allows for the application of a variety of Burkean frames and an even greater variety of conclusions to draw from them. The sequence involving Tony's gambling streak could even establish an argument counter to the one discussed above. The fact that Tony continues to 
gamble after killing Christopher (which was debatably an act of defiance against his father) indicates his ongoing rebellion against Johnny Boy's plans for Tony's future. Whereas Tony's gambling streak validates his mother's nihilistic philosophy, it contradicts his father's advice that gambling only leads to misery. One could even argue that when Tony amasses his fortune at the roulette wheel and says, "he's dead," he is referring more to Johnny Boy than to Christopher. Johnny Boy has of course been dead for years, but Tony has finally "killed him" through his vicarious patricide and proven him wrong by finding success in disobeying him. From Tony's perspective, Johnny Boy is now dead after, like Livia, controlling Tony as a harbinger of his depression for decades after his death. All ethics and morality aside, this sequence also adds to Tony's relatability. We (hopefully) have no experience murdering family members, but maybe we should all aspire to vicariously "murder" the mental images we carry of our parents, especially when those images stem from a history of childhood abuse. When we carry emotional trauma well into adulthood, and there is no way to reconcile our repressed rage with our deceased parents, perhaps a metaphorical patricide and/or matricide are our only options. If Tony could never forgive his parents for forcing him into a life of danger and existential dread, he can at least "kill" them the way a Wiccan might burn rosemary and sage to rid their house of a wraith.

Tony appears to be aware of his rebellion against his parents during this sequence. He tells Melfi in the next episode that during his epiphany, he realized that "our mothers are bus drivers," and that when they leave, "we keep trying to get back on the bus" (Winter, 2007). Of course, this claim would suggest that Tony is rejecting his mother's nihilism instead of embracing it. Therefore, the final season of The Sopranos seems to depict depression as something too complex to simply be accepted or rejected in one context, as Tony reaches a 
breakthrough (one he never received in his therapy sessions with Melfi) by simultaneously embracing and defying his parents' actions that have resulted in his depression. Both forgiveness and vicarious murder in and of themselves might be insufficient in overcoming childhood trauma, especially when both factors seem equally plausible. Someone struggling with traumatic events from their upbringing might resent their parents for instilling in them a crippling inferiority complex, but they might periodically remember the affectionate moments their parents displayed. This dichotomy would likely render them unable to forgive or "murder" their mental images of their parents, in which case the only feasible option would be to accept that both the tender and vile qualities of their parents will always affect them. After all, The Sopranos taught viewers to perceive television characters like Tony as simultaneously sympathetic and revolting. Should we not attempt to understand the same complexity in our parents?

The final season of The Sopranos also relies on more subtle moments to suggest that depression can be mitigated by rejecting the actions and ideas of one's parents. In the series finale, Tony finds AJ the script reading job after having a discussion with his daughter Meadow, who has recently decided against her lifelong dream of going to medical school in favor of becoming a criminal defense lawyer (Chase, 2007). She tells Tony she changed career paths after seeing federal agents constantly arrest Tony with little to no due process. Tony ironically fails to prevent his children from becoming involved in the criminal lifestyle his own father forced him into, as it is Tony's involvement in the mafia that inspires Meadow to pursue a career that will presumably allow her to defend criminals in a similar industry. Tony consequently offers AJ the script reading job in the following scene. AJ might not be as intelligent or ambitious as his sister, but there is still hope for him to avoid the mafia lifestyle that has largely contributed to Tony's depression. Tony offering AJ the job is perhaps another way of rejecting the status quo that has 
plagued his family for generations. Rather than continuing the cycle of fathers enlisting their sons into the "family business," Tony rejects this cultural norm within the mafia to protect his son from it. In this case, he is not merely rejecting his father's desires, but he is defying the foundation on which his entire livelihood is built. The final season, as a result, fails to offer a single solution to the problem of family-based depression - the answer could involve embracing one's inescapable position within their family history of mental illness, but it could also include challenging those existing power structures that perpetuate an individual's depression from childhood to well into their adult years.

Further complicating the final season's argument about the process of overcoming depression as it relates to their family upbringing is how the show tends to frame the topic differently than its characters, as if the writers are asserting that the characters are trying to overcome their mental illness in a detrimental way. For instance, while Tony seems content when watching the sunrise after his gambling streak (whether it is due to his acceptance of his mother's perspective or the rejection of his father's), the presence of the ducks quacking could signify that Tony is actually "poisoning" his family by dwelling more on his deceased parents than the family members who currently need his help. In this case, perhaps the final season is arguing that when individuals attempt to overcome depression in a self-serving, misanthropic way, they do so at the expense of those they love most. Regardless of whether Tony is accepting or rejecting the status quo of his depression, the series might be using a grotesque frame to suggest that the viewer should reject Tony's hedonistic pursuit of a distraction from his "family curse." We should, the series might argue, be revolted by Tony's actions and should attempt to alter the standard self-serving ways of coping with depression that constantly tempt us. 
The final season of The Sopranos, then, offers multiple (if not contradicting) perspectives on how someone with a mental illness can treat their symptoms when they stem from interactions with family members. Such individuals might be able to mitigate their depression by rebelling against their parents' desires and worldviews, or they might find peace through relenting from that rebellion altogether and accepting that their symptoms, whether they are born from a set of "cursed" genes or a childhood history of emotional abuse, will be with them forever. And despite the apparent success or failure of the characters in The Sopranos in overcoming their depression, the series could be framing the topic in an entirely different way than those characters, one that challenges viewers to perceive television characters not as inspiring extensions of themselves or people they can "relate to," but as complex individuals to be scrutinized, criticized, or even ridiculed.

\section{Depression Resulting from an Existential Crisis}

An even more common theme related to depression in The Sopranos is the existential dread its characters face. While not part of this study's "sample" of the final season (and not exactly a type of intertextual data), several moments throughout the series indicate that the show's main characters are constantly concerned about the inevitable approach of death and the ambiguity surrounding what happens after we die. More specifically, the show often illustrates how characters use their day-to-day routines as distractions from this reality. The sixth season episode "Cold Stones" follows Tony dealing with the revelation of Vito's homosexuality and the various opinions of his crew about how to approach it (Frolov, Schneider, \& Chase, 2006). The title of the episode, however, derives from Carmela's trip to Italy, where she observes several gargoyles of notable Italians that are centuries old. During the trip, Carmela tells her friend Rosalie that Tony's first words after awakening from his coma were "Who am I?" and "Where 
am I going?" Carmela says she finally understands what Tony meant as she examines the gargoyles - even the most prominent and revered figures are eventually reduced to "cold stones," something we often fail to realize until confronted with death. Tony reiterates this sentiment to his rival crime boss Phil Leotardo after Phil has a heart attack just before the final season (Winter, Chase, \& Weiner, 2006). Tony tells him he "went some place" during his coma where he never wants to return and that "no one ever laid on their deathbed wishing they saved more no-show jobs." These moments illustrate the theme of characters distracting themselves from the inevitable nature of death yet momentarily vowing to prioritize the more valuable aspects of their lives (or, as Tony labels them, "the little things").

The series has hinted at this theme in the subtler moments before the final season as well. In "D-Girl," AJ endures an existential crisis after his English teacher assigns Albert Camus's The Stranger (Kessler, 2000). AJ steals Carmela's car, and when she tells him he could have killed someone, he shrugs and says, "Death just shows the ultimate absurdity of life." Tony and Carmela, concerned their already lethargic son will even further underperform in school, attempt to remind him of the family's Catholic values, to which AJ replies, "There is no God." Tony tells AJ that even if God is not real, AJ will still be "kissing his ass" while he lives under their roof. Later, when Melfi tells Tony that AJ might have stumbled upon existentialism, Tony blames the "fucking internet" (Kessler, 2000). From the beginning of the series, then, Tony and Carmela distract themselves from these existential concerns to instead focus on their traditional values. Thus, it is when AJ discusses these concerns with Livia that she recites her "it's all a big nothing" monologue (Kessler, 2000). Again, this example occurs much earlier than the final season, but it does showcase the show's general use of intertextual cues to suggest that while 
characters struggle with conflicts such as mob wars, infidelity, and family drama, the fear of death looms above them all.

\section{Religious and Spiritual Imagery}

The final season's intertextual framework related to existential depression is less preoccupied with references to pop culture and earlier moments in the series than allusions to spiritual messages related to the threat of death and judgment. In the series finale, after Phil murders much of Tony's crew, Tony offers to promote Paulie to the rank of captain (Chase, 2007). Paulie initially refuses, claiming he saw a vision of the Virgin Mary in the crew's strip

club. Paulie believes the crew is cursed and that his past misdeeds will haunt him if he continues down his current path. Tony's notable epiphany after ingesting peyote also includes several theological references (Weiner \& Chase, 2007). When Tony first takes the drug, he watches a bright light in the ceiling while sitting on the bathroom floor, as if he is aware of some deity waiting to exact retribution. Tony then goes downstairs to the hotel's casino and sees a slot machine with a devilish-looking logo on it. The slot machine's theme is related to Pompeii, the ancient city destroyed by the eruption of Mount Vesuvius, an event that some believe was a form of divine punishment, similar to God's destruction of Sodom and Gomorrah in the Bible (LaFrance, 2015). After his winning streak, Tony ventures into the desert to watch the sunrise (the setting and colors of which might be another reference to Hell) and witnesses a beacon of light before yelling his three-word realization. Of course, the white light could symbolize the same divine judgment Tony seemed to witness in the bathroom a few scenes prior, but it possesses a greater connection to the vision Tony encounters in his coma.

During the first episode involving Tony's coma (titled "Join the Club"), Tony finds himself in an alternate universe (the "place" he went that he warns Phil about) in which he is a 
traveling salesman named Kevin Finnerty (Chase \& Nutter, 2006). He is friendly, committed to helping his family even when away from home, and lacks his signature New Jersey accent, all signs of what his life could have been had his father not forced him into the "family business." When Tony (as Kevin Finnerty) sits in a hotel bar of the alternate universe, he sees both a television news report about rampant forest fires and a beacon of light in the distance, as if he is trapped between Heaven and Hell. Whether Tony is dreaming or existing in a sort of purgatory is never explained, but given the existential questions he later raises to Carmela and Phil, Tony clearly considers the vision's ramifications. In the second episode of Tony's coma (titled "Mayham"), Tony eventually finds the light's source to be a house in the woods of the alternate universe (Weiner, 2006). The house's inhabitants urge him to come inside. Tony refuses just before waking up from the coma. The light, then, seems to symbolize death in addition to (or in place of) the presence of a deity. Thus, it is when Tony wakes up from the coma and sees the Ojibwe saying on the wall that he tells Paulie to "get over this petty bullshit" because, according to Tony's new philosophy, we are all "part of something bigger" (Frolov \& Schneider, 2006). Whether Tony's coma visions have genuinely allowed him to see his own family issues as "petty" and stop distracting himself from his true values or if he is just irritated with Paulie is left open for interpretation. It is clear, though, that the series uses references to spiritual imagery (as well as meta-references to the show's own use of that imagery) to suggest that depression can result from existential concerns.

\section{"Strangers" to the "Absurdity of Life"}

Given the show's self-referential moment involving Tony witnessing the beacon of light before shouting his epiphany (and given that the beacon likely represents death), Tony seems to accept death's inevitable approach in that moment. After years of suppressing his fear with his 
business dealings and only occasionally acknowledging the brevity and value of his life, Tony finally accepts that he will end up in the same place as Christopher, his parents, and every other close acquaintance who is now six feet underground. Perhaps, similar to his possible acceptance of his mother's worldview in that moment, Tony accepts that death highlights the "absurdity of life" as AJ realized when reading The Stranger. This time, Tony does not attribute that type of absurdism or nihilism to the internet, but to a profound realization he is only able to understand after literally getting away with murder. Maybe this realization is also why, in another selfreferential moment, Tony is reminded in the penultimate episode of the series, "The Blue Comet," of a conversation he had with his brother-in-law Bobby while they were at his lake house (Chase \& Weiner, 2007). Tony and Bobby speculate at the lake house about the experience of being murdered, with Bobby saying, "You probably don't even hear it when it happens" (Frolov, Schneider, Chase, \& Weiner, 2007). Tony flashes back to this moment as he lies in bed after Bobby has been murdered by Phil's crew (Chase \& Weiner, 2007). Then he sleeps soundly with his rifle next to him. Tony's supposed tranquility in this moment, despite him being a prime target for Phil in the largest mob conflict of the series, seems to stem from his newfound awareness that death is inevitable. It is not exactly an earth-shattering fact, and Tony of all people should be constantly aware of it given his line of work. However, Tony's coma experience ironically seemed to exacerbate his fear of death because he literally walked away from it in his visions, making him even more fearful of what could have been. His recognition of the beacon of light indicates his acceptance that death is an inescapable constraint, one he paradoxically overcomes by understanding it will happen to all of us.

Perhaps, though, Tony's realization is more complex than accepting the inevitability of death. Tony might be content with the increasingly likely prospect of death during his peyote 
trip, but he witnesses what might be the most morbid experiences of his life in the few remaining episodes, chief among them being his son's suicide attempt (Winter, 2007) as well as the murder and presumed murder of Bobby and Silvio, respectively (Chase \& Weiner, 2007). The most harrowing of these seems to be one that occurs in the series finale after Tony is still able to sleep soundly following Bobby's death: his last encounter with his uncle Junior. Junior caused both of Tony's closest near-death experiences. Following Livia's indirect orders, he hired the hitmen for Tony's assassination attempt in the first season episode "Isabella" (Green \& Burgess, 1999), and he shot Tony in the episode "Members Only" when his dementia caused him to believe Tony was a rival mob boss (Winter, 2006). In the series finale, "Made in America," Junior is placed in a state facility with little more than a window and a television set (Chase, 2007). In the penultimate scene of the series finale, Tony visits Junior in the facility to make arrangements for the money Tony wants to send to Bobby's children (Chase, 2007). At first, Junior does not recognize Tony because of his dementia. Tony is not surprised, given that Junior has not recognized Tony since he shot him. However, Junior does briefly recognize Tony at the end of their conversation. Tony reminds Junior that he and Johnny Boy ran North Jersey together. Junior shrugs and says, "That's nice" and returns to looking out the window of the facility. Tony then leaves with tears in his eyes. Tony's epiphany in Las Vegas seemed to alleviate Tony's existential depression when he accepted that death was inevitable (Weiner \& Chase, 2007). Now, though, Tony sees just how lonely and debilitating that worldview is. It further cements Livia's point that Tony appeared to embrace during his peyote trip - Junior will presumably "die in his own arms," and life must be "a big nothing" if on our deathbeds we care more about looking out the window than reflecting on our careers. In theory, then, Tony should be delighted to see the 
evidence behind both his initial philosophy of embracing the "little things" and his newfound acceptance of his mother's nihilism.

Perhaps Tony's tears in his final scene with Junior stem from Tony realizing that he still has yet to overcome his existential depression. The symptoms might be briefly subsided after his epiphany, but he still has not changed his views in practice. Just like he was unable to appreciate the nature at the lake house with Bobby (Frolov, Schneider, Chase, \& Weiner, 2007) or enjoy watching the waves at the beach with Paulie (Winter, 2007), Tony is more determined to find meaning in the distractions of his mafia dealings than in the values he professed to his family. He sees that despite his moment of clarity and his current success escaping death from rival crime leaders and incarceration from the FBI, his best-case scenario is to spend his twilight years alone in a state facility like his uncle. His mother was right, but the future seems undoubtedly bleaker in reality. If the intertextuality of Tony's peyote trip urges us to accept our inability to overcome childhood trauma, Tony's final conversation with Junior warns of us of the resulting distress when that acceptance prevents us from perceiving simple, daily experiences as rewarding opportunities instead of trivial chores.

The final season's placement of this scene between Tony and Junior toward the end of the series finale expands on the show's argument about overcoming existential depression - this type of depression, as the show presents it, might be periodically abated with brief realizations and breakthroughs, but the only way for individuals to overcome (or at least treat) its symptoms is through the long-term practice of those realizations, something viewers never see Tony do. Thus, overcoming this type of depression is not as simple as "accepting" or "rejecting" the status quo or a certain belief system. Tony stills "accepts" his mother's nihilistic philosophy after his conversation with Junior, considering Junior possesses all the symptoms of Livia's notable 
monologue. However, Tony appears to change his emotional attitude regarding that philosophy, having transitioned from screaming with tears of joy to walking away with tears of dread at the same realization. From a Burkean lens, the final season suggests that one can start to overcome their existential depression by accepting a nihilistic worldview before adapting to their surroundings to enjoy what time they have left. After all, where Tony differs from his mother is how he chooses to live in response to that philosophy, even if the viewer only sees his actions in one scene following his last conversation with Junior.

The final scene of the series is the first (and possibly last, depending on one's interpretation of the scene) time Tony follows the mantra he has now embraced after years of denying it. He has dinner with his family at the diner, orders some onion rings for them before each family member arrives, and plays “Don't Stop Believin"” on the jukebox (Chase, 2007), all of which represent the "little things" he has failed to enjoy for so long and that he does not want to wait to understand until he has dementia and lives alone in a state facility. The common thread among all those "little things" seems to be elements of the physical, material world. If the universe is inherently meaningless like Livia suggested years ago, Tony might as well embrace the only aspect of life he is guaranteed. His song choice in the diner paradoxically represents him believing in nothing spiritual. Rather, he chooses to believe in the physical moments with his family, like sharing onion rings and playing a song on the jukebox. If these are his final moments on Earth, he wants to spend them not in a grandiose shootout with rival mob leaders, but in the quiet moments with his loved ones. The same way the sequence involving Tony's peyote trip refuses to offer a simple solution to overcoming one's childhood trauma, this scene in the diner fails to present a miracle drug to cure one's existential misery. The threat of death and eternal nothingness will always loom in the subconscious of someone like Tony Soprano, and an infinite 
number of spiritual awakenings or hallucinogenic experiences could never change that. But believing in those "little things" that might not represent a belief system at all provides an opportunity to experience some semblance of joy before we spend our final moments alone in a state facility.

Another reason Tony seems to acquire this aspect of his mother's nihilism can be seen through the intertextual references to his death in the diner. No familiar characters other than Tony’s immediate family exist in this final scene (Chase, 2007), but the "strangers" (as mentioned in the Journey song) in the diner represent death in some way to Tony. He first sees an elderly man sitting alone like Junior. Tony then sees two younger black men, and it was two black men who tried to murder Tony on the orders of Junior and Livia. This interpretation would obviously be racist out of context, but because the scene is shot from Tony's perspective, and because Tony has a history of blaming black men for a number of crimes (Weiner \& Winter, 2004), the sight of two black men likely represents death to Tony in some capacity. The most prominent symbol of death, though, occurs in the scene's final moments, when a mysterious man eyes Tony suspiciously before walking into the restroom. Given Tony's preestablished fixation with gangster films, he is undoubtedly familiar with the scene in the first Godfather film in which Michael Corleone retrieves a pistol from the restroom before committing a murder in a restaurant (Ruddy, 1972). These various references remind Tony he could die at any moment, which is likely why he continues to make conversation with his family and eat the onion rings he ordered for the table. Perhaps this sequence, then, solidifies the final season's argument that to overcome the depressive symptoms precipitated by an existential crisis, one must accept a nihilistic worldview before consequently finding some type of "spiritual" meaning in the physical world around us. 
It is this aspect of the final season's argument that makes its earlier reference to The Stranger seem less like a minor subplot halfway through the second season and more like a thematic allusion to the show's core philosophy. AJ probably tells his parents that "death just shows the ultimate absurdity of life" (Kessler, 2000) as a snide remark to justify his juvenile behavior, but intentionally or not, the final season uses that philosophy to address what depressed individuals should do in response. For instance, The Stranger follows a man named Meursault, who is arrested for murdering a man in cold blood (Camus, 1946). He is eventually sentenced to death, but the jury's reasoning behind the decision has little to do with the motive behind the murder - the critical decision comes after Meursault reveals he spent the day after his mother's death going swimming and watching movies with his girlfriend. The jury assumes he must be a sociopath for not mourning the way society expects. The morning of his execution, Meursault recognizes himself as a "stranger" who believes that the tangible aspects of the world are the only source of meaning one can find. As he enjoys the sights and smells of daybreak (even in his cold and empty jail cell, not unlike Junior's unofficial deathbed), he realizes he failed to mourn his mother not because he did not love her, but because he believed that physical pleasures are all life guarantees. As a result, the combination of literary and spiritual references in the final season of The Sopranos and the modification of the way Tony accepts a nihilistic worldview reveals the show's core argument - one can overcome their existential dread by accepting the universe's random and impartial qualities and consequently directing their focus to the minor, tangible rewards that everyone (including a mob boss) can experience.

\section{The Tragedy of Material Goods}

Of course, the cinematic complexity of the final scene allows for myriad interpretations from this perspective. For instance, the fact that Tony spends his entire time at the diner scanning 
the room for potential murderers (Chase, 2007) could indicate that the paranoia and morbidity of the lifestyle his father coerced him into has rendered him unable to enjoy the "little things" he holds valuable. If this is the case, Tony has "accepted" this aspect of his line of work, which might be an even greater tragedy than the possibility that he is shot in the diner -- regardless of whether he dies at the end of that scene or alone in a state facility in 40 years, he will presumably spend his final moments terrified of the prospect of death rather than appreciating the subtle yet significant details around him. He has resigned himself to the status quo of being the "leader of North Jersey" and avoided every opportunity to become an FBI informant and leave the life that brought him decades of misery (which admittedly would have presented its own series of challenges).

Even the final season's depiction of the "little things" themselves as elements of the material and physical world can be interpreted in several ways, similar to the show's complex (and potentially contradictory) stance on overcoming depression stemming from family experiences. One of the primary reasons Tony admits he is depressed in the pilot is because he believes he "came up in at the end," after the golden age of the mafia (Chase, 1999). He expected the luxurious benefits of being in the mafia bestowed upon his ancestors and those presented in popular culture, like Al Capone, Henry Hill, and Charles "Lucky" Luciano. What Tony received instead was a suburban house with a swimming pool and two kids who constantly disobey their parents. In that case, Tony has failed from the beginning - the pursuit of wealth and material goods (and other "little things" of the sort) were the source of his depression all along. Those same "little things" also erode his brief "life is precious" philosophy after he awakens from his coma. When Tony discusses his dilemma regarding Vito's homosexuality with Melfi (his first major conflict when re-entering the business), Tony complains that despite his new "stop and 
smell the roses" mentality, "regular life has a way of picking away at you... the shit you own... your house... your kids... trying to work a cell phone menu is enough to make you scream" (Chase, Winter, Green, \& Burgess, 2006). It is then that Tony adds the "pair of socks" element to his "every day is a gift" philosophy. Tony strays from his coma-induced realization simply because of the irritation behind material goods and other miscellaneous "little things." Perhaps, then, the final season could be viewed through a grotesque frame, as the viewer should be disgusted by Tony's inability to appreciate the subtle moments he claims are key to long-term happiness. As a result, The Sopranos might argue that throughout all of Tony's amoral actions (murder, extortion, adultery, etc.), one of his greatest sins is toward his own well-being, and we should be horrified by his materialistic pursuits, as if the prospect of wealth deceived him as a source of satisfaction, when in reality it drove him away from a true source of prosperity. Tony's inability to understand the materialistic source of his depression acts as a parable for us to reject a capitalist culture that exists outside of the mafia. Like Tony, we too might have let a specific "system" tempt us with material goods, whether it is through advertisements, corporate agendas, or some other entity that distracts us from the "little things" that offer a more long-term, sustainable form satisfaction.

The series also warns against the pursuit of material wealth through other prominent intertextual references. The episode including Tony's peyote trip in Las Vegas involves a subplot with AJ taking a literature class (Weiner \& Chase, 2007). His professor reads an excerpt from Wordsworth's "The World is Too Much With Us" while posing the question, "Why such strong words against the material world?" This moment plays between scenes of Tony arriving in Las Vegas, resuming his gambling addiction, and meeting Christopher's ex-girlfriend. Although Tony seems content in the moment (resulting in his eventual epiphany at the end of the episode), 
the episode's inclusion of Wordsworth's poem seems to suggest otherwise in the long-term. The sonnet was written as a critique against the First Industrial Revolution and Western society’s greater emphasis on material wealth than its relationship with nature (University of Delaware, 2020). The episode's placement of this reference between scenes of Tony's hedonistic actions alludes to the show's possible argument that materialistic desires, despite their ephemeral euphoria, will ultimately result in greater existential misery. While Tony might be accepting the inevitable nature of death and submitting to materialistic impulses as a result, the show might simultaneously be rejecting that way of life and urging viewers to place a more potent emphasis on the more natural elements of their existence.

The final season uses a similar approach in specifically chronicling Tony's gambling addiction. When Tony first develops his addiction in the final season, his associate Carlo references an episode of The Twilight Zone called "A Nice Place to Visit" (Weiner, 2007). This episode of The Twilight Zone follows a career criminal named Henry Valentine (Beaumont, 1960). Valentine is killed in a police shoot-out and enters an afterlife in which all his wishes are granted. Valentine wins every game of blackjack and roulette, and he receives his first choice of sex workers when he requests them. By the end of the episode, Valentine becomes bored with the monotony of the afterlife and asks the deity who brought him there if he can go to the "other place" for a change. The deity laughs and replies, "This is the other place." Of course, The Sopranos only references this episode of The Twilight Zone in passing, but the clear parallels between the gambling addictions of Tony and Valentine appear more than coincidental. The difference, though, is that the viewer witnesses the eventual tragedy of Valentine's story -- the episode strongly indicates Valentine will literally spend an eternity chasing a high that only results in a series of diminishing returns. Tony, however, only shows signs of rage and anxiety 
during his losing streak (Weiner, 2007). He is elated while winning at the roulette wheel during his peyote trip (Weiner \& Chase, 2007). Therefore, despite the aforementioned evidence suggesting Tony starts to overcome his depression during this epiphany, the intertextual reference to Valentine's misery indicates that Tony might end up like Valentine, forever pursuing a level of euphoria he will never achieve. Through this reference, then, the final season of The Sopranos seems to reject the blind pursuit of material wealth, urging viewers to perceive Tony through a grotesque frame and avoid his actions that will only magnify his depressive symptoms.

These intertextual hints further complicate the ambiguity of Tony's breakthroughs that, on the surface, highlight the cure to Tony's depression. Melfi does commend Tony's insight regarding his peyote trip and the "bus" metaphor (Winter, 2007), but Tony might not even understand the epiphany himself. He stutters several times and changes certain aspects of the metaphor as he recites it. He then trails off at the end and claims he lost his train of thought. Between the parallels to Valentine's story and Tony's inability to articulate his "breakthroughs," the final season of The Sopranos might be challenging viewers to see Tony's mental health beyond his own perspective. While the show never depicts Tony’s eventual downfall like Valentine's (at least not as overtly), perhaps it invites the viewer to witness Tony's lack of insight. By framing Tony's story through more of a rejection than acceptance, the final season resembles a parable instead of a redemption story -- we should be disgusted by Tony's inability to apply his several years of therapy to his mental health, and we are more likely to achieve some form of spiritual enlightenment if we acknowledge the "grotesque" behavior of Tony, Valentine, and Meursault. This philosophy is of course at odds with the final season's evidence suggesting that overcoming depression can result from an acceptance of materialistic pursuits. The show 
might not offer one consistent, concrete solution to overcoming depression resulting from an existential crisis (or any other type of depression for that matter), but it does raise a number of questions and perspectives to inspire and invite viewers to apply their perspectives to the insight they gain from witnessing Tony's experiences.

\section{The Relationship Between Media Platforms and Depression}

Perhaps the most prominent use of intertextuality in The Sopranos involves the relationships between its characters and various contemporary media devices of their era. Characters often seem engaged in (or at least aware of) popular films, television shows, and music that was either relevant during the show's popularity or relevant to a certain character's childhood (Ambrose, 2019). In fact, these media interactions extend beyond ways characters cope with and make sense of their mental illness - media artifacts in several forms are a way for

the characters to make sense of their existence in general. In the second episode of the series, "46 Long," Tony and his crew are watching a news report of a former mafia member who became an FBI informant (Chase, 1999). Tony asks Silvio to "cheer him up," at which point Silvio quotes a line from Michael Corleone in The Godfather Part III while doing an impersonation of Al Pacino. From the beginning of the series, then, the show's characters involved in organized crime are invested in current news reports on the subject, but they also care deeply about classic gangster films, even using them as an emotional crutch when they sense their careers becoming obsolete in a new generation.

In the second season episode "Commendatori," Tony's crew receives a bootleg DVD of The Godfather Part II, and their DVD player starts malfunctioning as soon as the film starts, ironically freezing on the "FBI Warning" screen (Chase, 2000). While they wait for the DVD to load, each member of the crew shares their favorite moments from the film. They can even quote 
specific scenes verbatim. They also mention how much they love the scenes that take place in Italy, the "mother country" to everyone in the crew and the location of their business meeting in the same episode. Tony mentions how excited he is to see all the beautiful scenery the way it is depicted in the film only to be disappointed by how different and "commercialized" the area has become once they arrive. The characters affiliated with the mafia in The Sopranos therefore rely on their favorite films in the gangster genre not simply as a source of entertainment, but as a representation of what they think their lives should be. This disconnect between fiction and reality might be why Tony tells Melfi in the pilot that he "came in at the end" and that "the best is over" (Chase, 1999). Films like The Godfather (intentionally or not) portrayed the mafia lifestyle as something glamorous to Tony, leaving him saddened by the triviality of its day-today responsibilities.

The inaccurate portrayal of the mafia also affects Tony's children throughout the series. In the season four episode "Everybody hurts," AJ visits his girlfriend Devin to find she lives in a mansion with several expensive collector's items scattered around the first floor alone. AJ is disheartened upon seeing the mansion, presumably because he expects his family to have the most luxurious property of all his friends, especially compared to those not involved in the mafia. AJ more explicitly reveals his inability to distinguish between his reality and that depicted by popular gangster films when Tony recovers from his coma. In the sixth season episode "Johnny Cakes," AJ brings a knife to Junior's nursing home with the intent to kill him (Frolov \& Schneider, 2006). AJ accidentally drops the knife as soon as he enters the room. The orderlies then escort him out of the building and require Tony to pick him up from the nursing home. When Tony reprimands AJ, AJ calls Tony a hypocrite, arguing that Tony enjoys the violent scenes in The Godfather films but does not approve of his son doing the same thing. Tony 
reminds AJ that those films are fiction and should have no effect on the viewers' actions. In the same scene, however, Tony berates AJ for doing "nothing" in his failed attempt at murder and calls him a "fucking jerkoff." While Tony seems more aware of the disconnect that contributed to his depression at the beginning of the series, he also expects AJ to possess some sort of finesse for the violent actions of which mob figures are stereotypically capable (and the kind Tony's own father expected of him). On some level, then, Tony is still subconsciously driven by the gangster films that inspired him as a child.

\section{Media Platforms as Tools for Coping with Depression}

Although each season of The Sopranos is inundated with references to popular culture (specifically as it relates to the gangster genre), such references are most related to those characters' mental illness in the final season. AJ, for instance, relies on popular media forms to cope with his depression from his fiancé leaving him, with some considering it a way for him to "sulk." AJ watches violent television shows like the adult cartoon Metalocalypse and plays the first-person shooter Halo (Chase \& Weiner, 2007). He reads news stories from Al Jazeera about the war in Iraq and listens to music with morbid lyrics (Winter, 2007), such as the song "Into the Ocean" by Blue October, a song about someone committing suicide after losing a loved one (Furstenfeld, 2006). AJ even becomes furious with his sister Meadow when she tries to turn the music's volume down. AJ's song choice is obviously reminiscent of his own feelings toward losing his fiancé, but his indulgence in violent media (especially about the conflict in the Middle East) further reveals his capacity to catastrophize his emotions. He does not simply want to confirm his own dread following his breakup - he wants to believe the entire world is rife with misfortune (Winter, 2007). He wants to believe Tony's philosophy that our lives are a "miserable fucking existence" (Winter, 2007). As a result, this overt use of intertextuality in the final season 
argues that individuals with depression often turn to contemporary media devices not only to confirm their distressing emotions, but as an outlet to catastrophize them even further.

AJ even uses non-violent media programs as a way to catastrophize. After Bobby's funeral, when someone asks if anyone has seen film Dreamgirls, AJ tells everyone at the table that they are "living in a dream" because they spend too much time watching the Academy Awards and American Idol to realize how awful the world is (Chase, 2007). However, like other characters in the final season, $\mathrm{AJ}$ falls victim to the tendency of using popular media texts as a distraction from depressive symptoms. AJ also watches shows like Tom and Jerry (Winter, 2007) and commercials for sleeping pills (Winter, 2007) when he is depressed. In both the nursing home and the state facility, Junior copes with his sense of isolation by watching game shows like Jeopardy and Wheel of Fortune (Winter, 2007). After Christopher's death in "Kennedy and Heidi," Carmela watches part of The Dick Cavett show when she is unable to sleep (Weiner \& Chase, 2007). None of these programs are known for violence or covering topics like mental illness. They are typically a source of light entertainment, which is likely why these characters indulge in them - they are the few sources of reprieve from characters' depressive symptoms.

Characters in the final season also use television to alleviate the more "mundane" types of depression that Tony laments at the beginning of the series. For example, Melfi has her own therapist, Elliot Kuperberg, to whom she complains about Tony's inability to change after years of treating him (Chase \& Weiner, 2007). Elliot offers Melfi advice throughout the series possibly as a gesture of goodwill, but also because he is fascinated by the psyche of the criminal underworld. These "meta-therapy" sessions allow Elliot to live vicariously through Melfi's experiences of trying to treat a career criminal. Thus, in the final season, Elliot watches The 
Geraldo Rivera Show covering the current state of the American mafia (Winter, 2007). Elliot's indulgence in popular media is similar to other characters' use of media texts to alleviate their depression, although Elliot seems to treat media as a source of excitement rather than a comforting distraction from chaos. Ironically, Elliot is awed by the contemporary American mafia, when it is the mundane and prosaic nature of the business that contributed to Tony's depression in the first place. From the perspective of The Sopranos, the fixation on popular media texts as a distraction from depressive symptoms is not limited to criminals. All of us, regardless of our mental health, are prone to relying on extravagant narratives relayed through contemporary media platforms for some form of amusement.

Despite its portrayal of contemporary media devices as a temporary crutch for those suffering from depression, the final season of The Sopranos does use its intertextuality to present the use of these devices as a communal (if not therapeutic) experience. As mentioned previously, Tony's warped sense of masculinity prevents him from empathizing with AJ's depression (Winter, 2007), even though he endures the mental illness himself. His advice to AJ is limited to "walk like a man" and "go out and get a blowjob." Tony even tells Melfi he becomes depressed himself when he sees AJ "curled up on the couch in a 'fetus' position when he should be out banging coeds" (Winter, 2007). However, while Tony fails to offer AJ any therapeutic guidance, he does bond with him through the television programs AJ watches. Tony observes AJ with disgust when AJ is watching reruns of Tom and Jerry (Winter, 2007), but he sits down and watches with him when $\mathrm{AJ}$ is watching Annapolis, a film about several students at the United States Naval Academy competing in a boxing tournament (Saccani \& Vahradian, 2006). Perhaps Tony is only able to empathize with AJ when he subscribes to Tony's masculine interests. Similarly, when AJ is rapidly cycling through several channels, Tony tells him to stop when he 
sees a channel playing Hellfighters (Winter, 2007), a film about a group of elite firefighters starring John Wayne (Arthur, 1968). It is then that Tony recommends AJ attend a party at a strip club and Carmela reprimands Tony for encouraging their depressed son's night of debauchery (Winter, 2007). Yet, despite Carmela's disapproval of Tony and AJ's behavior, the episode ends with the entire Soprano family sitting down for dinner because Carmela and Meadow became hungry after watching Rachel Ray on The Tonight Show with Jay Leno. The final season of The Sopranos, as a result, frames contemporary media texts as an excuse for someone with depression to catastrophize their emotions and engage in self-pity, but it also considers them a conduit for family bonding when family members fail to communicate their complex and often disturbing impulses. Similar to the final season's suggestion that we reconcile the contradictory qualities of our parents, The Sopranos refrains from lionizing or condemning modern media devices. Rather, they are tools for making sense of our mental health, the effects of which are too varied and complicated to be labeled as "good" or "bad."

\section{Depression's "Second Coming”}

The episode "Walk Like a Man" is not the only episode title in the final season taken from an existing text (Winter, 2007). The later episode "The Second Coming" follows AJ continuing his literature class where he has transitioned from reading Wordsworth to the titular poem by Yeats (Winter, 2007). AJ seems more fascinated by this poem than anything else in his academic career - he actively listens to his literature professor quote lines about how "Surely some revelation is at hand." He then reads the poem at home before going to bed, engaged by the prospect of some "rough beast" that "slouches towards Bethlehem to be born" (Yeats, 1921). Many scholars argue that the poem, which literally describes the apocalyptic Second Coming of Jesus Christ, functions as an allegory for post-war Europe after World War I (Tabor, 2015; 
Albright, 1997). The poem warns that the worst was yet to come, despite those blindly hopeful after the war. Perhaps the final season's incorporation of this text during a pivotal moment in AJ's depression signifies a similar pattern, albeit in a much different context. Overcoming depression is not a linear process, and we should be appropriately skeptical toward apparent breakthroughs and realizations - the "center" can stop "holding" at any time. The episode directly before "The Second Coming" finds AJ committed to his coursework and living a normal life, something his therapist compliments him on (Weiner \& Chase, 2007). Then he witnesses the attack on the Somali boy, a random incident that has nothing to do with the initial cause of his depression. However, the attack was enough to cause AJ's mind to spiral and for him to attempt suicide in the next episode. To be cliché, AJ's depression had to get worse before improving. It is this tragic portrayal of depression that establishes the show's frame of acceptance toward overcoming depression - the "good times" Tony values are infrequent enough for anyone, let alone for those struggling with a mental illness. The only way for such individuals to alleviate their symptoms is to accept that those moments are mere reprieves from their constant emotional turmoil.

The final season applies this nonlinear model of overcoming depression to the characters' specific interactions with contemporary media texts. In the mental hospital, AJ watches a commercial for Rozerem in which Abraham Lincoln and a groundhog tell a man they miss seeing him in his dreams because he hardly sleeps anymore (Winter, 2007). AJ smiles when the commercial cites statistics for the number of American adults suffering from insomnia. This 30second advertisement alleviates AJ's sense of solitude - although his family and therapist were unable to offer him the guidance or empathy to prevent his suicide attempt, AJ does seem to feel less alone because of a contemporary media text, a vast departure from his reaction to reading $A l$ 
Jazeera's reports of the U.S.'s involvement in the Middle East. However, it is in the next episode that $\mathrm{AJ}$ begins watching a violent episode of Metalocalypse and shooting monsters in Halo (Chase \& Weiner, 2007). One of his first actions after returning home from the hospital is watching an episode of PBS's America at a Crossroads about the ongoing war in Iraq, after which he resumes his frequent monologues about the "messed up" state of the world (Chase \& Weiner, 2007). One's indulgence in these forms of media, the final season ostensibly argues, can provide a sense of relief from depressive symptoms, but the "second coming" is bound to occur before long - a sole reliance on commercials or television programs does not provide a stable foundation or "center," one that surely "cannot hold" indefinitely. From a Burkean lens, we should "accept" the status quo that clinical depression is too powerful for an individual to overcome through watching a television series or even a commercial - they need a more permanent and more social solution to cure (or at least treat) their incessant feeling of hopelessness.

\section{Media Platforms as a Scapegoat}

Although the final season of The Sopranos has little faith in contemporary media devices' long-term ability to treat depression, it avoids portraying those devices as the sole or primary cause of one's depressive and suicidal behavior. In doing so, the final season depicts its characters personifying that "anti-media" perspective. While AJ's suicide attempt occurs after his budding interest in poetry and news reports of the war in Iraq (Winter, 2007), his family becomes increasingly unempathetic toward his mental health. When AJ confesses his sense of hopelessness about the world to Meadow, she tells him he needs to learn to "shut stuff out" (Winter, 2007), an arguably pat and reductive solution to a complex problem. In addition to Meadow's lack of empathy toward AJ (and Tony's inability to identify with AJ beyond critically 
panned John Wayne films), Carmela also demonstrates the capacity to scapegoat media texts for her son's depression and suicide attempt. Early in "The Second Coming," when AJ develops his interest in Yeats, Carmela claims, "he's actually reading" and that "this can't be bad." After his suicide attempt later in the episode and the subsequent family intervention, Carmela questions, "What kind of poem is that to teach college students?" (Winter, 2007). Carmela initially believes in the benefits of AJ's education, but denounces it when his depression worsens. Guilt-ridden as they might be, Tony and Carmela refuse to accept their responsibility to help their son mitigate his depressive symptoms, instead electing to blame a poem about post-war Europe.

Tony and Carmela's scapegoating of the poem reflects another of Burke's ideas, that of mortification and victimage. Burke (1969) argues in his Iron Law of History that individuals who have disrupted the order of society might resort to "mortification" as a form of self-sacrifice to alleviate their guilt and allow for "purification." However, when mortification is not possible, the offender might instead resort to victimage and project their guilt upon a scapegoat (Burke, 1969). Tony and Carmela's scapegoating of the Yeats poem likely results from their refusal to accept responsibility for their child's psychological wellbeing. They no longer need to acknowledge their "cursed" family history when they can blame something that is not an extension of themselves. This sequence in the final season, then, urges us to confront the unsettling aspects of our lineage and communicate openly with our family members. Otherwise, we are doomed to end up like Carmela smiling and washing dishes, blissfully ignorant of AJ continuing to watch media coverage of the Iraq War as his only source of companionship after leaving the mental hospital (Chase \& Weiner, 2007).

While the final season appears to argue that individuals with depression should "accept" that media devices alone are insufficient resources to support one's mental health, it might be 
using a grotesque frame of rejection in its presentation of AJ's family. Despite having first-hand experience with mental illness themselves, some parents of children with similar illnesses refuse to acknowledge their own role in treating their children. As viewers, perhaps we should be horrified by Tony and Carmela's inability to help AJ the way Tony's parents refused to help him understand the "cursed Soprano gene." We should instead, the final season claims, understand the limitations of media devices in regard to coping with depression. No matter how much we relate to a song about heartbreak-induced suicide or a documentary featuring copious amounts of violence, the only long-term solution to mitigating depressive symptoms is to connect with those who understand us on a personal level.

Further illustrating this rejection of a family's lack of communication regarding mental illness is the content of the show's televisual intertextual references. The episode of The Dick Cavett Show Carmela watches features an interview with Katharine Hepburn (Weiner \& Chase, 2007). In this short segment of the interview, Hepburn says she could receive virtually any role she wanted early in her acting career, given her effortless ability to feign any emotion imaginable during her auditions (Doumanian \& Lloyd, 1973). However, she would make countless mistakes once she was inevitably offered the role - she could only convey happiness, sadness, or any other mood for so long before her appearance lacked authenticity (Doumanian \& Lloyd, 1973). The same idea could likely be applied to depression - a member of a family (or any social compact) that refuses to openly discuss mental health without judgment is (consciously or not) forced to "play the part" of someone without a mental illness. And the same way Katharine Hepburn would eventually lose her ability to maintain that identity, The Sopranos appears to suggest that someone pretending to be "normal" in a society that fails to understand mental illness will suffer for it as well. That prospect seems clear for Tony, as he has presumably struggled with the same 
thing. His mother, despite battling a mental illness herself, was incapable of expressing affection for Tony. Ironically, Tony is engaging in a similar performance when he and Carmela watch The Dick Cavett show but in the opposite form. Tony is relieved at ridding himself of his "biggest blunder" when killing Christopher, but he has to pretend to grieve at Christopher's funeral (Weiner \& Chase, 2007). In either case, the show's incorporation of the Katharine Hepburn interview suggests that open communication about mental health among family members is essential to treating mental illness, regardless of the short-term benefits of watching television and assuming a false identity of someone without depression. Although we might be able to convince our closest allies of our mental stability, the façade is likely to fade in abrupt, detrimental ways, not unlike faltering in a dramatic performance or fainting after watching a family of ducks leave a swimming pool.

\section{Taking Advice from Television}

Another of the final season's "meta" references to other television programs not only condemns the sole reliance on television as a cure for depression, but it seems to mock itself in the process. In the series finale, as Tony and his crew hide in a safehouse from Phil's imminent retribution, a different episode of The Twilight Zone plays in the background (Chase, 2007). Titled "The Bard," this episode follows a talentless television writer, Julius Moomer, hopelessly pitching ideas to a television executive (Serling, 1963). When Moomer uses black magic to summon William Shakespeare as his ghostwriter, Shakespeare writes a script with enough obscure prose and archaic dialogue to convince the executive that the script possesses the literary merit to be successful. The episode appears to be a commentary on viewers' capacity to overanalyze art (specifically television) that has either been met with critical acclaim or resembles a style that would be hailed by critics. The Sopranos' sampling of this episode might 
serve to diminish its own status as a television show - even if viewers and critics alike have largely considered it the greatest television series of all time, this intertextual reference reminds us that it is, after all, still just a television series, and anyone who, like AJ, tries to find some form of therapeutic meaning in it will ultimately suffer from their own deteriorating mental health. This potential grotesque frame from The Sopranos could be applied to parents who refuse to see the more complex causes of depression beyond a television show, but it could also describe those who elevate a television series (even one as acclaimed and respected as The Sopranos) beyond its intended purpose to entertain. Perhaps as viewers of the series finale, we should be disgusted at how we have placed a greater emphasis on a fictional crime family in New Jersey to make sense of our personal problems than supporting each other interpersonally. We should feel ashamed for neglecting our peers and consider turning off the television before finishing the final episode - the 50 minutes of the episode that continue after this reference to The Twilight Zone are 50 minutes we could spend with someone so distraught their significant other left them that they might not be alive tomorrow.

The final season's intertextuality in asserting this argument is not limited to television and popular, accessible forms of media. For instance, when Melfi has dinner with Elliot and some of her other colleagues toward the end of the series (Chase \& Weiner, 2007), Elliot reveals to everyone that Melfi has been treating Tony Soprano, a name everyone recognizes from the local news. Elliot then mentions a series of studies in a book called The Criminal Personality by Yochelson and Samenow (1976). These studies, he claims, examined the use of talk therapy on imprisoned sociopaths. The researchers found that this form of therapy enabled the sociopaths in the study's sample to be better criminals, as if a more adept understanding of the human psyche helped them "sharpen their skills" on their therapists through "crocodile tears" and other forms 
of deception (Chase \& Weiner, 2007). Melfi reads the study herself later in the episode, finding that the results also reveal that sociopaths often express affection through animals rather than humans. Melfi then impulsively tells Tony in their next session that she can no longer treat him and asks him to leave. Some fans and critics found this sequence abrupt and oversimplified, despite its possible argument that hardened criminals cannot change their behavior, at least not without significant reflection and determination (VanDerWerff, 2012). Perhaps, though, the abrupt dissolution of Tony and Melfi's relationship highlights a crucial aspect of final season's argument, one that revolves around those who treat mental illness rather those who suffer from it.

Melfi has always functioned as an "audience surrogate" in the series. She learns about Tony the way viewers do, listening to his childhood stories and trying to understand the nature of his mental illness. Like viewers, Melfi is equally repulsed and fascinated by his actions, which is arguably why she continues to treat him despite her professional instincts. The tragic end to Melfi and Tony's relationship might serve to punish viewers for sympathizing with a sociopath who, regardless of his likable qualities, is still a murderer and a career criminal. He is still the man who strangled someone for becoming an FBI informant (Manos Jr. \& Chase, 1999) and suffocated his nephew for his inability to overcome his heroin addiction (Weiner \& Chase, 2007). Maybe, like Melfi, viewers should be disgusted with themselves for allowing a criminal's mental illness to cloud their judgment. Maybe these tragic character arcs (in which Tony's flaws have rendered him unable to use his therapeutic insight for anything other than antisocial behavior) suggest we should accept that misanthropic individuals with a mental illness are untreatable. No psychiatric revolution or significant degree of insight is enough to treat sociopaths with a mental illness, and they are doomed to be miserable the rest of their lives. 
After years of lying to herself either because she was fascinated by Tony's actions or because of her blind faith in Tony's ability to change, Melfi becomes one of the show's only heroes when she no longer allows herself to enable someone as despicable as Tony, a kind of acceptance viewers should presumably follow after witnessing this realization from their audience surrogate.

Contrarily, Melfi's abrupt choice to end her professional relationship with Tony could possess an entirely different implication. After years of working with Tony and trying to understand the root of his depression, she makes a definitive and irreversible decision based on one study she did not know existed before this episode. She places more emphasis on another text than her years of experience examining Tony herself (not to mention her decades of professional experience studying and practicing psychotherapy), the same way AJ blindly believes in the corruption behind the war in Iraq after reading one article in Al Jazeera or the way Tony embraces a criminal lifestyle because The Godfather promised him a luxurious existence. Melfi's failure to serve her patients through her own professional insight might best be explained through a grotesque Burkean frame of rejection - we should be horrified by Melfi's actions almost as much as Tony's, as this type of behavior perpetuates a reductive and ineffective way to treat someone with a mental illness. When we place a greater emphasis on one other text than the empirical knowledge we have gained ourselves, we risk becoming like Tony and Carmela, refusing to have a productive and nuanced conversation about mental illness. Therefore, the final season might use its intertextuality to condemn the reliance on other texts for the treatment of mental illness, even if those texts exist in a more reputable form or genre than Tom and Jerry reruns.

Of course, even if the final season of The Sopranos argues against the overreliance on contemporary and popular forms of media to treat depression, the series still illustrates the 
communal benefits of consuming them. After all, it is Rachel Ray's appearance on The Tonight Show that convinces the Soprano family to have dinner together and briefly forget the turmoil in their own lives (Winter, 2007). It is Junior's acceptance of his worsening dementia that encourages him to sing "Take Me Home, Country Roads" with his new friends in the nursing home and enjoy what little time he has left (Winter, 2007). It is AJ's experience spending time with his girlfriend watching President George W. Bush dancing with the KanKouran West African Dance Company on television that allows him to forget about his vendetta against the Bush Administration and "focus on the good times" as Tony has professed (Chase, 2007). And it is Tony's viewing of a scene from the film Little Miss Sunshine as he sits at Silvio's bedside during his coma (from which Silvio will likely never recover) that inspires Tony to visit Junior one last time after he is transferred to a state facility (Chase, 2007). The scene is brief and seemingly inconsequential - it depicts a young girl screaming with joy at the prospect of competing in a beauty pageant, something completely unrelated to Tony's predicament. It does, however, remind Tony of the "little moments" he still deems valuable, proving that even a life ranging from mundane to irritating to downright repulsive is still worth living. Throughout the final season's myriad references to the detrimental impact of indulging in certain media forms (particularly television), The Sopranos simultaneously positions these media forms as a healthy way to cope with mental illness, one that does not involve "sulking" or engaging in self-pity. It instead argues that because these platforms are (and will likely always be) a constant part of our culture, we should accept their ubiquitous presence and use them as tools to foster strong relationships with our loved ones. Just like how Tony plays a Journey song in a diner during what might be his final moments alive (Chase, 2007), we can seek out a song or a film or a 
television program that inspires us to share an onion ring with someone for whom we care deeply but never knew how to express it. 


\section{CHAPTER V: DISCUSSION}

Through its expansion on previous research, its combination of various methods, and the observations in its analysis, this study reveals the rhetorical merit of a television series like The Sopranos. In addition to its numerous accolades and extensive praise well after its infamous "cut-to-black" finale, The Sopranos proves to be a complex artifact worthy of scrutiny and evaluation. Its nuanced and multidimensional characters allow for myriad insights into the subject of mental illness alone. Researchers interested in other critical subjects could analyze several other issues the series raises, possibly through a completely different lens. Of course, this study is not without its flaws, as it is incapable of addressing and dissecting every critical concept presented in The Sopranos. But in addition to enlightening existing research on The Sopranos and mental health, this study seeks to challenge readers on the subject. As the researcher, I want people to evaluate their own experiences with mental health after considering Tony's complicated journey with depression. Therefore, between its applications to future research and the reaction it intends to elicit from its readers, this study will ideally have a lasting impact on this culturally relevant text.

\section{Directions for Future Research}

As with any study, this project seeks to inspire other researchers to elaborate on its scope and ideas, perhaps even through a similar lens. Because this study primarily examines the final season of The Sopranos, future studies could apply a Burkean and/or intertextual framework to another season in the series. Other seasons might use similar methods to convey arguments about the experience of mental illness in ways this study had not considered. Future researchers might identify other patterns of mental illness in those seasons, such as different characters suffering in different ways. Perhaps depression is not the only prominent area of mental health presented in 
the series. Junior's dementia gradually affects his memory and other cognitive functions throughout the latter half of the series. Elliot prescribes Melfi medication to treat obsessive compulsive disorder. The possibilities for future applications of mental health seem endless, especially given the lack of Burkean and intertextual methods used in current research on The Sopranos.

A handful of pivotal intertextual moments also exist in the final season that simply did not coincide with this study's focus. For instance, in the episode "Kennedy and Heidi," Christopher plays a live version of Pink Floyd's "Comfortably Numb" in his car stereo (Weiner \& Chase, 2007). Christopher mentions that he is playing the song from the soundtrack to the film The Departed. It is when the song begins playing that Tony realizes Christopher is under the influence of heroin while driving (and when the car crashes that Tony kills him). The episode immediately before this sequence, "Walk Like a Man," depicts Tony singing the same Pink Floyd song as he walks downstairs in his house (Winter, 2007). The overt reference to the song and its diegetic appearance alone reveal its deliberate, thematic use in the series, especially considering its connection to a film about gangsters and the American mafia. Tony singing the song before this crucial event also indicates his personal connection to the song, one that might have an impact on his most definitive decision in the series. However, the absence of any concrete evidence linking this pattern to the topic of mental health rendered this data unrelated to the study.

The same issues arose in examining the use of diegetic music in the series finale, "Made in America." The episode opens with Tony listening to Vanilla Fudge's cover of "You Keep Me Hangin' On" (Chase, 2007). He drives to the safehouse containing his family during his conflict with Phil, and the song stops once he exits the car, revealing that Tony is listening to the song the 
same time as the audience (as opposed to it playing in the background as part of a soundtrack). The song plays again several scenes later in Phil's car when Tony's hitmen assassinate Phil. Similarly, Bob Dylan's “It's Alright Ma (I'm Only Bleeding)" plays while AJ and his new girlfriend Rhiannon drive to the middle of a forest. The car catches fire when AJ parks on a pile of leaves, exploding shortly after AJ and Rhiannon escape. The song stops playing the same time as the explosion, implying the diegetic source of the music similar to Tony's experience listening to the Vanilla Fudge song. These diegetic moments where the viewer experiences the music along with the characters adds additional meaning to Tony's choice to play "Don't Stop Believin"' in the diner, a song that also starts and (possibly) stops playing as Tony experiences it. Unfortunately, as interesting as these patterns might be, they too are unrelated to the topic of mental illness (at least on the surface), and their inclusion in the analysis chapter of this study would risk resembling the "Hey, look what I found!" mentality of a self-aggrandizing online forum rather than a focused rhetorical analysis.

However, even if no connections exist between the aforementioned intertextual references and the topic of mental illness, their inclusion in The Sopranos could be related to one of the other ubiquitous topics in the series. The Soprano family's strict Catholic background (and the hypocrisy of the characters practicing it) likely raises a number of research questions about organized religion alone. Likewise, Tony's scapegoating of black men for a variety of crimes (Imperioli, 2004) and his reference to Meadow's new boyfriend in the episode "Proshai, Livushka" as a "butterhead" (Chase, 2001) reveal the racial themes present in the show, another subject of potential scrutiny. Critical scholars might also consider how these moments intersect, such as when Tony disparages Vito for his homosexuality because of his religious beliefs (Chase, Winter, Green, \& Burgess, 2006), despite his capacity for everything from adultery to 
murder. Tony’s conservative, “Archie Bunker” attitude toward younger generations could inspire researchers to apply intertextual or Burkean methods to the show's political discourse. For instance, seasons of the series that aired prior to the terrorist attacks on $9 / 11$ might present characters' political beliefs differently than the later seasons. In that case, maybe AJ's political rants toward the end of the series function more as a political statement from The Sopranos than a critique on how individuals with depression use media platforms as coping devices. Regardless of the relationship between these potential topics and the current study's subject matter, this study should inspire future researchers to continue considering The Sopranos as the rich, complex text it is.

\section{"Just a TV Show"}

I would be lying if I said I did not have any doubts about this study. I often wondered if a social scientific approach that considered audience reactions and attitudes regarding mental health would have a greater impact than a rhetorical analysis. I wanted to prove that the magnum opus of my academic career was more than a self-absorbed "book club" that would (at best) be relegated to a blog about television dramas. Sure, this study lacks a social scientific approach that other scholars have applied to the topic of television and mental illness, but it uses its intertextual data to illuminate the human experience of psychological depression, as pretentious as that sounds. It considers complex ideas about mental illness and refuses to limit itself to a cookie cutter conversation about whether Tony dies in the series finale. It hopefully invites readers to reconsider the series (or really any aspect of mental health) in ways they have never considered. In fact, it was a written analysis of The Sopranos that first inspired this project. I read a book called TV (The Book), in which its authors rank the 100 greatest American television programs of all time (Sepinwall \& Seitz, 2016). I was surprised to see the authors rank 
The Sopranos as high as number 2 on their list - I had seen all the episodes of the series, but I had never perceived it as more than an entertaining drama about gangsters. Seitz and Sepinwall (2016) justify their decision by discussing the literary and psychological complexity of The Sopranos, claiming that while the series might not be as perfect as others on the list (due to its occasionally inconsistent and meandering plotlines), its robust examination of its protagonist establishes The Sopranos as one of the greatest works in the history of American television. I had never viewed the series for its detailed examination of Tony's psyche, and the authors' criticism inspired me to revisit it. Once I became obsessed with the series, I began questioning its applications to mental health in general. I asked my therapist if someone with a major depressive disorder could be so emotionally "walled off" that they can only express affection through animals. He said no, but the question did start an hourlong discussion about childhood trauma and its ramifications well into adulthood. That conversation led to my therapist and I discussing why, as a 25-year-old man, I still felt ashamed to disclose my struggles with mental health to my closest friends. It inspired me to challenge the ways I had been taught (consciously or not) to express my frustrations with my upbringing. And that was all because of what a few critics had to say about a television show.

I would be hesitant to suggest that a television series influenced any of my major life decisions, but it has impacted the way I perceive and understand mental health more than any other television series, or frankly any piece of art from the twentieth century. Countless film and television characters have possessed what appear to be accurate, relatable qualities of certain mental illnesses, but none have challenged my understanding of the topic more than Tony Soprano. Tony is more of a test subject than a character to be liked, idolized, or even related to (at least not on a literal level), a quality of The Sopranos that scholars interested in media effects 
might find worthy of examining. In terms of mental illness, are viewers of television dramas more interested in characters whose lives mirror their own, or do they better understand the experience of coping with mental illness when viewing characters like Tony Soprano? Is there an association between the depiction of a character like Tony Soprano and how audiences react to others with a mental illness? These questions are obviously beyond the scope of this study, but they do reveal the implications of this study's results.

If there is one glaring limitation to this study, however, it is the irony of its core argument. The analysis chapter observes the final season's apparent claim that individuals tend to rely too heavily on a television series for insight about their mental health, something this very chapter is guilty of doing. The Sopranos might be invalidating its status as anything more than an entertaining series about American gangsters. If that part of my argument is true, the rest of this study might be a shallow attempt to find meaning where none exists. Some of this study's readers might respond to the results the same way Tony sarcastically responds to Melfi in "The Strong, Silent Type" when she describes the process of interpreting one's dreams - "The gauhoxigogan is framed up by the ramistan" (Chase, Winter, Green, \& Burgess, 2002). But even if that is the most frequent reaction toward my thesis, and even if David Chase himself were to consider this a more incompetent analysis than AJ trying to understand "Stopping by Woods on a Snowy Evening” by the "Asshole Robert Frost" (Chase, 2001), then at least my research will have challenged someone to reconsider their views on an essential topic, the same way The Sopranos and a book ranking television shows inspired this project. 


\section{REFERENCES}

Albright, D. (1997). Quantum poetics: Yeats, Pound, Eliot, and the science of modernism. Cambridge: Cambridge University Press.

Amanullah, S. (2010). Destigmatising mental illness, House style. The British Journal of Psychiatry, 197(5), 377. doi:10.1192/bjp.197.5.377

Ambrose, K. (2019, May 22). 10 best pop culture references made on The Sopranos. Retrieved March 30, 2020, from https://screenrant.com/pop-culture-references-sporanos/

Anderson, M. J. (2008). Resurrecting the rube: Diegesis formation and contemporary trauma in Tony Scott's Déjà Vu. Film Criticism, 33(2), 2-22. Retrieved from http://libproxy.lib.ilstu.edu/login?url=https://search.ebscohost.com/login.aspx?direc $\mathrm{t}=$ true $\& \mathrm{db}=\mathrm{f} 3 \mathrm{~h} \& \mathrm{AN}=43235413 \&$ site $=$ ehost-live $\&$ scope $=$ site

Angeli, S. (2017). An unfinished mourning: Kenneth Lonergan's Manchester by the Sea (2016). New Cinemas: Journal of Contemporary Film, 15(2), 141-155. doi:10.1386/ncin.15.2.141_1

Appel, E. C. (1997). The rhetoric of Dr. Martin Luther King, Jr.: Comedy and context in tragic collision. Western Journal of Communication, 61(4), 376-402. doi:10.1080/10570319709374586

Armstrong, O. (2019). 7 surprises from The Sopranos 20th anniversary celebration. Retrieved from https://www.hbo.com/the-sopranos/20th-anniversary-split-screens-festival-panel2019

Arthur, R. (Producer), \& McLaglen, A. V. (Director). (1968). Hellfighters [Motion picture]. United States: Universal Pictures. 
Baker, J. (2004). The unhappiness of Tony Soprano: An ancient analysis. In R. Greene, \& P. Vernezze (Eds.), The Sopranos and philosophy: I kill therefore I am (pp. 28-36). Peru, IL: Carus Publishing Company.

Barreca, R. (Ed.). (2002). A sitdown with The Sopranos: Watching Italian American culture on TV's most talked-about series. Palgrave MacMillan.

Beal, J. A. (2018). 13 Reasons Why: A trigger for teen suicide? MCN: The American Journal of Maternal/Child Nursing, 43(1), 55. doi: 10.1097/NMC.0000000000000397

Beaumont, C. (Writer), \& Brahm, J. (Director). (1960, April 15). A nice place to visit [Television episode]. In R. Serling (Producer), The twilight zone. CBS.

Behrens, L. (1979). The argument in film: Applying rhetorical theory to film criticism. Journal of the University Film Association, 31(3), 3-11. Retrieved from http://www.jstor.org/stable/20687482

Biebel, B. (2010). Standing Up for Comedy: Kenneth Burke and The Office. The Journal of the Kenneth Burke Society, 7(1). Retrieved from https://www.kbjournal.org/biebel

Blake, R. A. (2017). Inside Bickle's brain: Scorsese, Schrader, and Wolfe on psychological realism. Journal of Popular Film \& Television, 45(3), 139-151. doi:10.1080/01956051.2017.1293604

Blistein, J. (2019). Sopranos' cast remembers James Gandolfini during 20th anniversary reunion. Retrieved from https://www.rollingstone.com/music/music-news/sopranos-cast-reunioninterview-today-777112/ 
Bridge, J. A., Greenhouse, J. B., Ruch, D., Stevens, J., Ackerman, J., Sheftall, A. H., . . Campo, J. V. (2019). Association between the release of Netflix's 13 Reasons Why and suicide rates in the United States: An interrupted time series analysis. Journal of the American Academy of Child \& Adolescent Psychiatry, doi:10.1016/j.jaac.2019.04.020

Burke, K. (1969). A rhetoric of motives. Berkeley: University of California Press.

Burke, K. (1984). Attitudes toward history (3rd ed.). Los Angeles, CA: University of California Press.

Camus, A. (1946). The stranger. Hamish Hamilton.

Carter, B. (2007, June 12). Reaction—Sopranos ending. The New York Times. Retrieved from https://www.nytimes.com/2007/06/12/arts/television/12sopr.html

Cavallero, J. J. (2004). Gangsters, fessos, tricksters, and Sopranos. Journal of Popular Film \& Television, 32(2), 50-63. doi:10.3200/JPFT.32.2.49-73

Chase, D. (Writer), \& Attias, D. (Director). (1999, January 17). 46 long [Television episode]. In D. Chase (Producer), The Sopranos. HBO.

Chase, D. (Writer), \& Nutter, D. (Director). (2006, March 19). Join the club [Television episode]. In D. Chase (Producer), The Sopranos. HBO.

Chase, D. (Writer), \& Patterson, J. (Director). (1999, April 4). I dream of Jeannie Cusamano [Television episode]. In D. Chase (Producer), The Sopranos. HBO.

Chase, D. (Writer), \& Van Patten, T. (Director). (2000, February 6). Commendatori [Television episode]. In D. Chase (Producer), The Sopranos. HBO.

Chase, D. (Writer/Director). (1999, January 10). The Sopranos [Television episode]. In D. Chase (Producer), The Sopranos. HBO. 
Chase, D. (Writer/Director). (2007, June 10). Made in America [Television episode]. In D. Chase (Producer), The Sopranos. HBO.

Chase, D., \& Kessler, T. A. (Writers), \& Patterson, J. (Director). (2000, April 9). Funhouse [Television episode]. In D. Chase (Producer), The Sopranos. HBO.

Chase, D., \& Konner, L. (Writers), \& Patterson, J. (Director). (2001, May 20). Army of one [Television episode]. In D. Chase (Producer), The Sopranos. HBO.

Chase, D., \& Renzulli, F. (Writers), \& Van Patten, T. (Director). (2001, May 13). Amour fou [Television episode]. In D. Chase (Producer), The Sopranos. HBO.

Chase, D., \& Weiner, M. (Writers), \& Taylor, A. (Director). (2007, June 3). The Blue Comet [Television episode]. In D. Chase (Producer), The Sopranos. HBO.

Chase, D., Winter, T., Green, R., \& Burgess, M. (Writers), \& Taylor, A. (Director). (2002, November 17). The strong, silent type [Television episode]. In D. Chase (Producer), The Sopranos. HBO.

Chase, D., Winter, T., Green, R., \& Burgess, M. (Writers), \& Van Patten, T. (Director). (2006, April 16). Live free or die [Television episode]. In D. Chase (Producer), The Sopranos. HBO.

Cheang, J., \& Doshi, S. (n.d.). How a video game could change the way we think about mental health. Retrieved February 23, 2020, from https://www.mhanational.org/blog/how-videogame-could-change-way-we-think-about-mental-health

Chory-Assad, R., \& Yanen, A. (2005). Hopelessness and loneliness as predictors of older adults' involvement with favorite television performers. Journal of Broadcasting \& Electronic Media, 49(2), 182-201. doi:10.1207/s15506878jobem4902_3 
Christiansen, A. E., \& Hanson, J. J. (1996). Comedy as cure for tragedy: ACT UP and the rhetoric of AIDS. Quarterly Journal of Speech, 82(2), 157-170.

Collins, S. (2016). Revisiting Boardwalk Empire, the most underappreciated drama of its time. Retrieved from https://www.vulture.com/2016/02/boardwalk-empire-is-the-mostunderrated-drama-of-its-time.html

Cooper, M. T., Jr., Bard, D., Wallace, R., Gillaspy, S., \& Deleon, S. (2019). A different perspective but consistent results: Another look at 13 Reasons Why. Journal of Adolescent Health, 64(3), 415-416. doi: 10.1016/j.jadohealth.2018.12.013

D’Angelo, F. J. (2009). The rhetoric of intertextuality. Rhetoric Review, 29(1), 31-47. doi:10.1080/07350190903415172

Dibeltulo, S. (2014). Family, gang and ethnicity in Italian-themed Hollywood gangster films. Film International, 12(4), 25-43. doi:10.1386/fiin.12.4.25_1

Diefenbach, D. L. (1997). The portrayal of mental illness on prime-time television. Journal of Community Psychology, 25(3), 289-302. doi:10.1002/(SICI)15206629(199705)25:3<289::AID-JCOP5>3.0.CO;2-R

Doohan, E.-A. M., Carrère, S., \& Riggs, M. L. (2010). Using relational stories to predict the trajectory toward marital dissolution: The oral history interview and spousal feelings of flooding, loneliness, and depression. Journal of Family Communication, 10(1), 57-77. doi:10.1080/15267430903396401

Doumanian, J., \& Lloyd, D. (Writers), \& Forrest, A. (Director). (1973, September 14). Katharine Hepburn: Part 1 [Television episode]. In The Dick Cavett show. ABC. 
Dumit, J. (2002). Is it me or my brain? depression and neuroscientific facts. Journal of Medical Humanities, 24(1), 35-47. Retrieved from http://libproxy.lib.ilstu.edu/login?url=https://search.ebscohost.com/login.aspx?direc $\mathrm{t}=$ true $\& \mathrm{db}=\mathrm{a} 9 \mathrm{~h} \& \mathrm{AN}=11303218 \&$ site $=$ ehost-live $\&$ scope $=$ site

Dunlap, K. (2018). Representation of mental illness in video games. Proceedings of the 2018 Connected Learning Summit, 77-86. Retrieved from https://www.researchgate.net/publication/334306891_Representation_of_Mental_Illness_ in_Video_Games

Dunne, S. L. (2002). The brutality of meat and the abruptness of seafood: Food, violence, and family in The Sopranos. In D. Lavery (Ed.), This thing of ours: Investigating The Sopranos (pp. 215-228). New York: Columbia University Press.

Dunst, C. (2020). BoJack Horseman ended with a necessary reckoning. Retrieved from https://www.nytimes.com/2020/02/01/opinion/bojack-horseman-final-season.html

Egner, J. (2019, January 7). David Chase on The Sopranos, Trump and, yes, that ending. The New York Times. Retrieved from https://www.nytimes.com/2019/01/07/arts/television/david-chase-sopranosinterview.html

Fans outraged by Sopranos' finale (2007). Retrieved from https://people.com/celebrity/fansoutraged-by-sopranos-finale/

Farkas, A. (2016). Organized chaos: Cohesive devices in Benjy's sections of William Faulkner's The Sound and The Fury. Acta Universitatis Sapientiae, Philologica, 8(2), 167-176. doi:10.1515/ausp-2016-0025 
Ferguson, C. J. (2018). 13 reasons why not: A methodological and meta-analytic review of evidence regarding suicide contagion by fictional media. Suicide and Life-Threatening Behavior, doi:10.1111/sltb.12517

Ferrari, M., McIlwaine, S. V., Jordan, G., Shah, J. L., Lal, S., \& Iyer, S. N. (2019). Gaming with stigma: Analysis of messages about mental illnesses in video games. JMIR Mental Health, 6(5). doi:10.2196/12418

Flamini, M. (2002). "Pa cent' anni, Dr. Melfi:" Psychotherapy in the Italian American community. In R. Barreca (Ed.), A sitdown with The Sopranos: Watching Italian American culture on TV's most talked-about series (pp. 113-128) Palgrave MacMillan.

Freedman, C. (2011). The supplement of Coppola: Primitive accumulation and The Godfather trilogy. Film International (16516826), 9(1), 8-41. doi:10.1386/fiin.9.1.8

Frolov, D., \& Schneider, A. (Writers), \& Taylor, A. (Director). (2006, April 2). The fleshy part of the thigh [Television episode]. In D. Chase (Producer), The Sopranos. HBO.

Frolov, D., \& Schneider, A. (Writers), \& Van Patten, T. (Director). (2006, April 30). Johnny cakes [Television episode]. In D. Chase (Producer), The Sopranos. HBO.

Frolov, D., Schneider, A., \& Chase, D. (Writers), \& Van Patten, T. (Director). (2006, May 21). Cold stones [Television episode]. In D. Chase (Producer), The Sopranos. HBO.

Frolov, D., Schneider, A., Chase, D., \& Weiner, M. (Writers), \& Van Patten, T. (Director). (2007, April 8). Soprano home movies [Television episode]. In D. Chase (Producer), The Sopranos. HBO.

Furstenfeld, J. (2006). Into the ocean. On Foiled [CD]. 
Gaedtke, A. (2014). Halluci-nation: Mental illness, modernity, and metaphoricity in Salman Rushdie's Midnight's Children. Contemporary Literature, 55(4), 701-725. doi:10.1353/cli.2014.0041

Gabriel, S., Read, J. P., Young, A. F., Bachrach, R. L., \& Troisi, J. D. (2017). Social surrogate use in those exposed to trauma: I get by with a little help from my (fictional) friends. Journal of Social and Clinical Psychology, 36(1), 41-63. doi:10.1521/jscp.2017.36.1.41

Gibson, B. (2006). "Black guys, my ass:" Uncovering the queerness of racism in The Sopranos. In D. Lavery (Ed.), Reading The Sopranos: Hit TV from HBO (pp. 194-213)

Glick, D., \& Applbaum, K. (2010). Dangerous noncompliance: A narrative analysis of a CNN special investigation of mental illness. Anthropology \& Medicine, 17(2), 229-244. doi:10.1080/13648470.2010.493605

Glynn, S., Kangas, K., \& Pickett, S. (n.d.). How to cope when a loved one has a serious mental illness. Retrieved February 22, 2020, from https://www.apa.org/helpcenter/seriousmental-illness

González, J. Á. (2019). 'Wiring' The Wire: Transtextual layers and tragic realism in The Wire. Journal of Popular Television, 7(3), 279-297.doi:10.1386/jptv_00002_1

Gorman, S. (2007). Sopranos rub-out theory gains credence. Retrieved from https://www.reuters.com/article/us-sopranos/sopranos-rub-out-theory-gainscredence-idUSN0644006120070615?pageNumber=1

Green, R., \& Burgess, M. (Writers), \& Coulter, A. (Director). (1999, March 28). Isabella [Television episode]. In D. Chase (Producer), The Sopranos. HBO. 
Grist, L. (2007). Masculinity, violence, resistance: A new psychoanalytic reading of Raging Bull. Atlantis, 29(1), 11-27. Retrieved from http://www.jstor.org/stable/41055263

Grist, L. (2016). The Aviator. Film International (16516826), 14(1), 102-119. doi:10.1386/fiin.14.1.102_1

Hanich, J., \& Menninghaus, W. (2017). Beyond sadness: The multi-emotional trajectory of melodrama. Cinema Journal, 56(4), 76-101. doi:10.1353/cj.2017.0041

Heffernan, N. (2017). Slum plays, salvation stories, and crook pictures: The gangster regeneration cycle and the prehistory of the gangster genre. Film History, 29(2), 32-65. doi:10.2979/filmhistory.29.2.02

Henderson, L. (2018). Popular television and public mental health: Creating media entertainment from mental distress. Critical Public Health, 28(1), 106-117. doi:10.1080/09581596.2017.1309007

Hoffner, C. A., \& Cohen, E. L. (2015). Portrayal of mental illness on the TV series Monk: Presumed influence and consequences of exposure. Health Communication, 30(10), 1046-1054. doi:10.1080/10410236.2014.917840

Horton, D., \& Wohl, R. R. (1956). Mass communication and para-social interaction. Psychiatry: Journal for the Study of Interpersonal Processes, 19, 215-229. Retrieved from http://libproxy.lib.ilstu.edu/login?url=https://search.ebscohost.com/login.aspx?direc $\mathrm{t}=$ true $\& \mathrm{db}=\mathrm{psyh} \& \mathrm{AN}=1957-06011-001 \&$ site $=$ ehost-live $\&$ scope $=$ site

How to stop catastrophizing. (n.d.). Retrieved April 4, 2020, from https://www.medicalnewstoday.com/articles/320844

Imperioli, M. (Writer), \& Bronchtein, H. J. (Director). (2000, March 12). From where to eternity [Television episode]. In D. Chase (Producer), The Sopranos. HBO. 
Imperioli, M. (Writer), \& Buscemi, S. (Director). (2002, October 20). Everybody hurts [Television episode]. In D. Chase (Producer), The Sopranos. HBO.

Johnson, J. (2010). The skeleton on the couch: The Eagleton affair, rhetorical disability, and the stigma of mental illness. Rhetoric Society Quarterly, 40(5), 459-478. doi:10.1080/02773945.2010.517234

Kanol, E. (n.d.). Glenn Beck's tragedy and Jon Stewart's comedy: Kenneth Burke's literary frames applied. Retrieved from https://www.academia.edu/9605999/Glenn_Beck_s_Tragedy_and_Jon_Stewart_s_Come dy_Kenneth_Burke_s_Literary_Frames_Applied

Kaplan, A. (2007). Mental illness on the screen: No more snake pit. (cover story). Psychiatric Times, 24(4), 1-7. Retrieved from https://www.psychiatrictimes.com/ptsd/mental-illnessscreen-no-more-snake-pit

Karthikeyan, S. (2013). A psychoanalytical study of D.H. Lawrence's Lady Chatterley's Lover. Language in India, 13(4), 142-145. Retrieved from http://libproxy.lib.ilstu.edu/login?url=https://search.ebscohost.com/login.aspx?direc $\mathrm{t}=$ true $\& \mathrm{db}=\mathrm{cms} \& \mathrm{AN}=87738778 \&$ site $=$ ehost-live $\&$ scope $=$ site

Kaźmierczak, M. (2019). Intertextuality as translation problem: Explicitness, recognisability and the case of "literatures of smaller nations," 362-382. doi:10.22363/2312-9182-2019-23-2362-382

Kessler, T. A. (Writer), \& Bronchtein, H. J. (Director). (2001, March 11). Fortunate son [Television episode]. In D. Chase (Producer), The Sopranos. HBO.

Kessler, T. A. (Writer), \& Coulter, A. (Director). (2000, February 27). D-Girl [Television episode]. In D. Chase (Producer), The Sopranos. HBO. 
Kristeva, J. (1986). The Kristeva reader (T. Moi, Ed.). New York: Columbia University Press.

LaFrance, A. (2015, October 2). Pompeii and the ancient origins of blaming the victim.

Retrieved April 4, 2020, from

https://www.theatlantic.com/technology/archive/2015/10/did-the-people-at-pompeii-getwhat-they-deserved/408586/

Larke-Walsh, G. (2012). The family curse: Mafia identity as inheritance in Abel Ferrara's The Funeral. Journal of Popular Film \& Television, 40(2), 75-82.

doi:10.1080/01956051.2011.636393

Leone, R., \& Peek, W. (2007). Gangster of love? Tony Soprano's assault on romantic myths. In M. Galician, \& D. Merskin (Eds.), Critical thinking about sex, love, and romance in the mass media (pp. 265-284)

Leverette, M. (2004). Deconstructing Larry, "the last man:” Larry David, Seinfeld, Curb Your Enthusiasm, and comedies of the self. Studies in Popular Culture, 27(1), 1-17. Retrieved from http://www.jstor.org/stable/23414973

Lewis, T. V. (2002). Religious rhetoric and the comic frame in The Simpsons. Journal of Media and Religion. doi:10.1207/S15328415JMR0103_2

Lewis, T. V., \& Molloy, K. A. (2015). Religious rhetoric and satire: Investigating the comic and burlesque frames within The Big Bang Theory. Journal of Media and Religion, 14(2), 88101. doi:10.1080/15348423.2015.1051457

Little, W. G. (2015). "Like an animal:" Figures on the move in The Godfather. Post Script, 34(2), 84-101. Retrieved from http://libproxy.lib.ilstu.edu/login?url=https://search.ebscohost.com/login.aspx?direc $\mathrm{t}=$ true $\& \mathrm{db}=\mathrm{f} 3 \mathrm{~h} \& \mathrm{AN}=118159250 \&$ site $=$ ehost-live $\&$ scope $=$ site 
Lueck, J. A. (2018). Respecting the "stages" of depression: Considering depression severity and readiness to seek help. Patient Education \& Counseling, 101(7), 1276-1282. doi:10.1016/j.pec.2018.02.007

Manos, J., Jr, \& Chase, D. (Writers), \& Coulter, A. (Director). (1999, February 7). College [Television episode]. In D. Chase (Producer), The Sopranos. HBO.

Marston, K. (2015). The tragic ballerina's shadow self: Troubling the political economy of melancholy in Black Swan. Quarterly Review of Film \& Video, 32(8), 695-711. doi:10.1080/10509208.2015.1060825

Martin, B. (2014). Difficult men: Behind the scenes of a creative revolution: From The Sopranos and The Wire to Mad Men and Breaking Bad. Penguin Books.

Mathivanan, S., \& Soundararajan, R. (2014). Foreordained final farewell and depression of Ivan Ilyich. Language in India, 14(1), 237-244. Retrieved from http://libproxy.lib.ilstu.edu/login?url=https://search.ebscohost.com/login.aspx?direc $\mathrm{t}=$ true $\& \mathrm{db}=\mathrm{cms} \& \mathrm{AN}=93457948 \&$ site $=$ ehost-live $\&$ scope $=$ site

McCabe, J., \& Akass, K. (2006). What has Carmela ever done for feminism? Carmela Soprano and the post-feminist dilemma. In D. Lavery (Ed.), Reading The Sopranos: Hit TV from $H B O$ (pp. 39-55)

McMahon, G. (2011). I'm as mad as hell, and I'm not going to take this anymore! Insane cinema. Film International (16516826), 9(3), 7-18. doi:10.1386/fint.9.3.8_1

Mental health disorder statistics (n.d.). Retrieved February 22, 2020, from https://www.hopkinsmedicine.org/health/wellness-and-prevention/mental-healthdisorder-statistics 
Mental illness and violence. (2011). Retrieved February 22, 2020, from https://www.health.harvard.edu/newsletter_article/mental-illness-and-violence Mental Illness in families. (2015). Retrieved February 22, 2020, from https://www.aacap.org/aacap/families_and_youth/facts_for_families/fff-guide/childrenof-parents-with-mental-illness-039.aspx

Mental illness (n.d.). Retrieved from https://www.mayoclinic.org/diseases-conditions/mentalillness/symptoms-causes/syc-20374968

Native American duck mythology. (2015). Retrieved April 15, 2020, from http://www.nativelanguages.org/legends-duck.htm

Nicholls, M. (2004). Male melancholia and Martin Scorsese's The Age of Innocence. Film Quarterly, 58(1), 25-35. doi:10.1525/fq.2004.58.1.25

Notredame, C.E., Grandgenèvre, P., Vaiva, G., \& Séguin, M. (2018). At least one more reason why. European Child \& Adolescent Psychiatry, 27(2), 259-260. doi:10.1007/s00787017-1033-8

Novak, P. (2019). "It's like waking:” Making meaning in and of Christopher Nolan's Memento. Journal of Film and Video, 71(4), 29-50. doi:10.5406/jfilmvideo.71.4.0029

O'Leary, T. (2009). Godfathers and sons: Tripping over the unconscious. FilmPhilosophy, 13(1), 38-52. doi:10.3366/film.2009.0003

Ott, B. L., \& Aoki, E. (2002). The politics of negotiating public tragedy: Media framing of the Matthew Shepard murder. Rhetoric and Public Affairs, 5(3), 483-505. Retrieved from https://www.jstor.org/stable/41939768 
Ott, B., \& Walter, C. (2000). Intertextuality: Interpretive practice and textual strategy. Critical Studies in Media Communication, 17(4), 429-446. doi:10.1080/15295030009388412

Palmer-Mehta, V. (2006). Disciplining the masculine: The disruptive power of Janice Soprano.

In D. Lavery (Ed.), Reading The Sopranos: Hit TV from HBO (pp. 56-68)

Parrott, S., \& Parrott, C. T. (2015). Law \& disorder: The portrayal of mental illness in US crime dramas. Journal of Broadcasting \& Electronic Media, 59(4), 640-657.

doi:10.1080/08838151.2015.1093486

Pheasant-Kelly, F. (2012). Institutions, identity and insanity: Abject spaces in Shutter

Island. New Review of Film \& Television Studies, 10(2), 212-229.

doi:10.1080/17400309.2012.658677

Pirkis, J., Blood, R. W., Francis, C., \& McCallum, K. (2006). On-screen portrayals of mental illness: Extent, nature, and impacts. Journal of Health Communication, 11(5), 523-541. doi:10.1080/10810730600755889

Riggs, E. E. (2018). Mental illness and the monstrous mother: A comparison of representation in The Babadook and Lights Out. Film Matters, 9(1), 30-38. doi:10.1386/fm.9.1.30_1

Roberts, M. (2006). Scarface, The Great Gatsby, and the American Dream. Literature Film Quarterly, 34(1), 71-78. Retrieved from http://libproxy.lib.ilstu.edu/login?url=https://search.ebscohost.com/login.aspx?direc $\mathrm{t}=$ true $\& \mathrm{db}=\mathrm{f} 3 \mathrm{~h} \& \mathrm{AN}=19974974 \&$ site $=$ ehost-live $\&$ scope $=$ site

Ruddy, A. S. (Producer), \& Coppola, F. F. (Director). (1972). The godfather [Motion picture]. United States: Paramount Pictures.

Ryan, M. (2007). Chase took easy way out with Sopranos. Retrieved from https://www.chicagotribune.com/news/ct-xpm-2007-06-14-0706120470-story.html 
Saccani, D., \& Vahradian, M. (Producers), \& Lin, J. (Director). (2006). Annapolis [Motion picture]. United States: Buena Vista Pictures.

Salter, M., \& Byrne, P. (2000). The stigma of mental illness: How you can use the media to reduce it. Psychiatric Bulletin, 24(8), 281-283. doi:10.1192/pb.24.8.281

Santo, A. (2002). "Fat fuck! why don't you take a look in the mirror?" Weight, body image, and masculinity in The Sopranos. In D. Lavery (Ed.), This thing of ours: Investigating The Sopranos (pp. 72-94). New York: Columbia University Press.

Scicurious. (2013, September 13). The IgNobels, 2013: Reattachment of the penis. Unless it was first eaten by a duck. Retrieved April 15, 2020, from https://blogs.scientificamerican.com/scicurious-brain/the-ignobels-2013-reattachment-ofthe-penis-unless-it-was-first-eaten-by-a-duck/

Sciullo, N. J. (2019). Justified's visual rhetoric: Television's subtle unmasking of the myth of the South. Journal of Visual Literacy, 38(4), 335-349. doi:10.1080/1051144X.2019.1690320

Sears, J. (1995). Crimewatch and the rhetoric of verisimilitude. Critical Survey, 7(1), 51-58. Retrieved from http://www.jstor.org/stable/41555884

Sepinwall, A. (2007, June 12,). David Chase speaks! The Star-Ledger.

Sepinwall, A., \& Seitz, M. Z. (2016). TV (the book): Two experts pick the greatest American shows of all time. New York: Grand Central.

Serling, R. (Writer), \& Butler, D. (Director). (1963, May 23). The bard [Television episode]. In R. Serling (Producer), The twilight zone. CBS.

Shadoian, J. (1979). Dreams and dead ends: The American gangster/crime film. Cambridge, Mass.: MIT Press. 
Shapiro, S., \& Rotter, M. (2016). Graphic depictions: Portrayals of mental illness in video games. Journal of Forensic Sciences, 61(6), 1592-1595. doi:10.1111/1556-4029.13214

Sheldon, Z. (2019). Hell house or something more? Horror, abjection and mental illness. Northern Lights: Film \& Media Studies Yearbook, 17(1), 43-56. doi:10.1386/nl_00004_1

Sieff, E. M. (2003). Media frames of mental illnesses: The potential impact of negative frames. Journal of Mental Health, 12(3), 259-269. doi:10.1080/0963823031000118249

Signorielli, N. (1989). The stigma of mental illness on television. Journal of Broadcasting \& Electronic Media, 33(3), 325-331. doi:10.1080/08838158909364085

Six common depression types. (2018). Retrieved from https://www.health.harvard.edu/mindand-mood/six-common-depression-types

Sopranos creator on "pissed" fans. (2007). Retrieved from https://ew.com/article/2007/10/18/sopranos-creator-pissed-fans/

Sopranos ratings beat most network shows. (2007). Retrieved November 13, 2019, from https://www.today.com/popculture/sopranos-ratings-beat-most-network-showswbna19194093

Spieker, L. (2017). House, Monk, Dexter, and Hannibal: "Super-powered" mentally ill TV characters. In S. Packer (Ed.), Mental illness in popular culture (pp. 159-168). Santa Barbara, CA: Praeger/ABC-CLIO.

Stoehr, K. (2004). "It's all a big nothing:" The nihilistic vision of The Sopranos. In R. Greene, \& P. Vernezze (Eds.), The Sopranos and philosophy: I kill therefore I am (pp. 37-47). Peru, IL: Carus Publishing Company. 
Stone, H. J. (2018). "A crater in the mind:" Seismic shifts in Mormon ideologies of mental illness. Religious Communication Association. Retrieved from http://libproxy.lib.ilstu.edu/login?url=https://search.ebscohost.com/login.aspx?direc $\mathrm{t}=$ true $\& \mathrm{db}=\mathrm{cms} \& \mathrm{AN}=132829782 \&$ site $=$ ehost-live $\&$ scope $=$ site

Storhoff, G. (2004). "A prisoner of forever:" Cognitive distortions and depression in John Okada's No-No Boy. Interdisciplinary Literary Studies, 6(1), 1-20. Retrieved from http://www.jstor.org/stable/41207035

Stuart, H. (2003). Violence and mental illness: An overview. World Psychiatry, 2(2), 121-124. Retrieved from https://www.ncbi.nlm.nih.gov/pmc/articles/PMC1525086/

Suicide Prevention. (2018). Retrieved February 22, 2020, from https://www.psychiatry.org/patients-families/suicide-prevention

Tabor, N. (2015, April 7). No slouch. Retrieved April 4, 2020, from https://www.theparisreview.org/blog/2015/04/07/no-slouch/

The 20 best TV dramas since The Sopranos. (2019, Jan 10,). Retrieved from https://www.nytimes.com/interactive/2019/arts/television/best-drama-series.html

The Sopranos | Television Academy. (n.d.). Retrieved November 13, 2019, from https://www.emmys.com/shows/sopranos

Thomas, E. (2019). Trump's claims and what experts say about mental illness and mass shootings. Retrieved February 22, 2020, from https://abcnews.go.com/Politics/trumpsclaims-experts-mental-illness-mass-shootings/story?id=65101823

Tony's vicarious patricide [Blog post]. (2009).

VanDerWerff, E. T. (2012, December 12). The Sopranos: “The Blue Comet.” Retrieved March 30, 2020, from https://tv.avclub.com/the-sopranos-the-blue-comet-1798175267 
Vendler, H. (2000). Lowell's persistence: The forms depression makes. The Kenyon Review, 22(1), 216-233. Retrieved from http://www.jstor.org/stable/4338003

Vincent, C. (2008). Paying respect to The Sopranos: A psychosocial analysis. Jefferson, NC: McFarland \& Company.

Wahl, O. F., \& Lefkowits, J. Y. (1989). Impact of a television film on attitudes toward mental illness. American Journal of Community Psychology, 17(4), 521-528. doi:10.1007/BF00931176

Wahl, O., Hanrahan, E., Karl, K., Lasher, E., \& Swaye, J. (2007). The depiction of mental illness in children's television programs. Journal of Community Psychology, 35(1), 121-133. doi:10.1002/jcop.20138

Walker, K. K., \& Burns, K. (2019). \#13ReasonsWhy health professionals and educators are tweeting: A systematic analysis of uses and perceptions of show content and learning outcomes. Health Communication, 34(10), 1085-1094.

doi:10.1080/10410236.2018.1461171

Weiner, M. (2011). Television Academy Interviews. Retrieved from https://interviews.televisionacademy.com/interviews/matthew-weiner

Weiner, M. (Writer), \& Bender, J. (Director). (2006, March 26). Mayham [Television episode]. In D. Chase (Producer), The Sopranos. HBO.

Weiner, M. (Writer), \& Van Patten, T. (Director). (2007, April 29). Chasing it [Television episode]. In D. Chase (Producer), The Sopranos. HBO.

Weiner, M., \& Chase, D. (Writers), \& Taylor, A. (Director). (2007, May 13). Kennedy and Heidi [Television episode]. In D. Chase (Producer), The Sopranos. HBO. 
Weiner, M., \& Winter, T. (Writers), \& Van Patten, T. (Director). (2004, May 2). Unidentified black males [Television episode]. In D. Chase (Producer), The Sopranos. HBO.

White, L. (2008a). Narratives of mental illness: The "autobiographical manifestos" of Kate Millett, Susanna Kaysen, and Kay Redfield Jamison. Women \& Language, 31(1), 4-12. Retrieved from http://libproxy.lib.ilstu.edu/login?url=https://search.ebscohost.com/login.aspx?direc $\mathrm{t}=$ true $\& \mathrm{db}=\mathrm{cms} \& \mathrm{AN}=34155252 \&$ site $=$ ehost-live $\&$ scope $=$ site

Wilson, C., Nairn, R., Coverdale, J., \& Panapa, A. (1999a). Constructing mental illness as dangerous: A pilot study. Australian and New Zealand Journal of Psychiatry, 33(2), 240247. doi:10.1046/j.1440-1614.1999.00542.x

Wilson, C., Nairn, R., Coverdale, J., \& Panapa, A. (2000). How mental illness is portrayed in children's television: A prospective study. The British Journal of Psychiatry, 176, 440443. doi:10.1192/bjp.176.5.440

Winter, T. (Writer), \& Abraham, P. (Director). (2007, April 22). Remember when [Television episode]. In D. Chase (Producer), The Sopranos. HBO.

Winter, T. (Writer), \& Taylor, A. (Director). (2007, April 15). Stage 5 [Television episode]. In D. Chase (Producer), The Sopranos. HBO.

Winter, T. (Writer), \& Van Patten, T. (Director). (2006, March 12). Members only [Television episode]. In D. Chase (Producer), The Sopranos. HBO.

Winter, T. (Writer), \& Van Patten, T. (Director). (2007, May 20). The Second Coming [Television episode]. In D. Chase (Producer), The Sopranos. HBO.

Winter, T. (Writer/Director). (2007, May 6). Walk like a man [Television episode]. In D. Chase (Producer), The Sopranos. HBO. 
Winter, T., Chase, D., \& Weiner, M. (Writers), \& Taylor, A. (Director). (2006, June 4). Kaisha [Television episode]. In D. Chase (Producer), The Sopranos. HBO.

Wondemaghen, M. (2019). Homeland and its use of bipolar disorder for sensationalist and dramatic effect. Social Semiotics, 29(2), 131-144. doi:10.1080/10350330.2017.1422900

Wordsworth's the world is too much with us. (n.d.). Retrieved March 30, 2020, from https://sites.udel.edu/britlitwiki/wordsworths-the-world-is-too-much-with-us/

Yeats, W. B. (1921). Michael Robartes and the dancer. Kessinger.

Yochelson, S., \& Samenow, S. E. (1976). The criminal personality: A profile for change. New York: Jason Aronson.

Zoromski, B (2007). The Sopranos: "Made in America" review. Retrieved from https://www.ign.com/articles/2007/06/11/the-sopranos-made-in-america-review 